$$
\text { DOEPC192148--Ti7 }
$$

\title{
DIRECT LIQUEFACTION PROOF-OF-CONCEPT PROGRAM
} Hydrocarbon Technologies, Inc., Lawrenceville, N.J.

\author{
A.G. Comolli \\ V.R. Pradhan \\ T.L.K. Lee \\ W.F. Karolkiewicz \\ G. Popper
FINAL
Topical Report
Bench Run 4 (227-95)

Work Performed Under Contract No. AC22-92PC92148

By

Hydrocarbon Technologies Inc., Lawrenceville, NJ,

CLEARED BY

PATENT COUNSEL

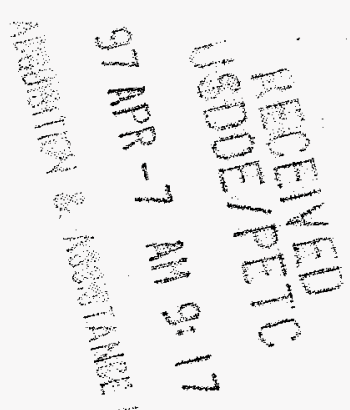

\author{
For \\ U.S. Department of Energy \\ Pittsburgh Energy Technology Center
}




\section{DISCLAMIER}

Portions of this document may be illegible in electronic image products. Images are produced from the best available original docoment. 


\section{DIRECT LIQUEFACTION PROOF-OF-CONCEPT PROGRAM Hydrocarbon Technologies, Inc., Lawrenceville, N.J.}
A.G. Comolli
V.R. Pradhan
T.L.K. Lee
W.F. Karolkiewicz
G. Popper

\section{FINAL}

RECEIVED

JUN 111997

OSTI

Topical Report

Bench Run 04 (227-95)

Work Performed Under Contract No. AC22-92PC92148

For

U.S. Department of Energy

Pittsburgh Energy Technology Center

By

Hydrocarbon Technologies Inc., Lawrenceville, NJ, 


\section{TABLE OF CONTENTS}

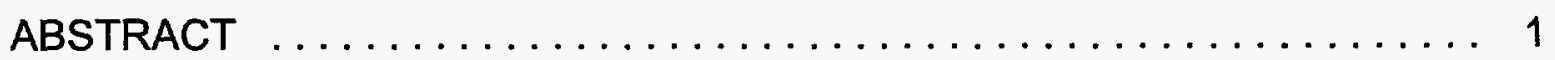

EXECUTIVE SUMMARY $\ldots \ldots \ldots \ldots \ldots \ldots \ldots \ldots \ldots \ldots \ldots \ldots$

BACKGROUND, OBJECTIVE, AND SCOPE OF WORK $\ldots \ldots \ldots \ldots \ldots \ldots 3$

SYSTEM CONFIGURATION $\ldots \ldots \ldots \ldots \ldots \ldots \ldots \ldots \ldots \ldots \ldots$

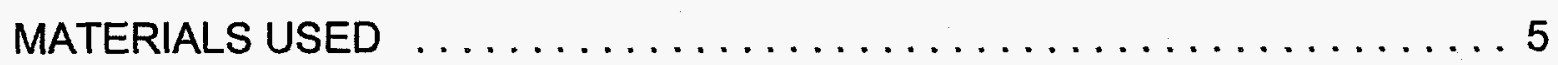

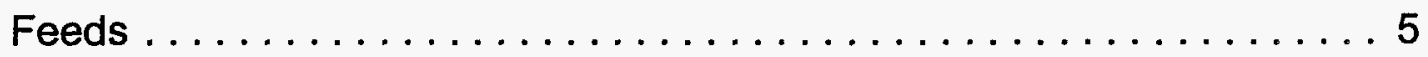

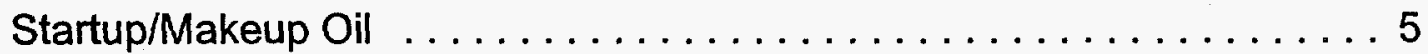

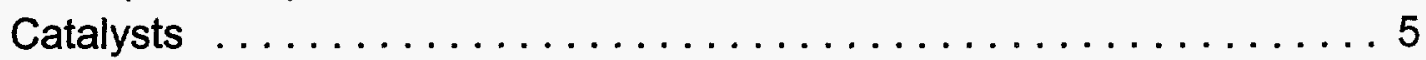

INTERSTAGE SLURRY SAMPLES $\ldots \ldots \ldots \ldots \ldots \ldots \ldots \ldots \ldots \ldots$

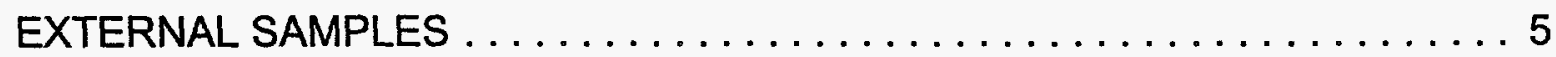

SUMMARY OF OPERATIONS $\ldots \ldots \ldots \ldots \ldots \ldots \ldots \ldots \ldots \ldots \ldots \ldots \ldots$

Unit Modification and Configuration $\ldots \ldots \ldots \ldots \ldots \ldots \ldots \ldots$

Dispersed Catalyst Preparation . . . . . . . . . . . . . . 6

Auto-Shredder Residue Preparation $\ldots \ldots \ldots \ldots \ldots \ldots \ldots \ldots 6$

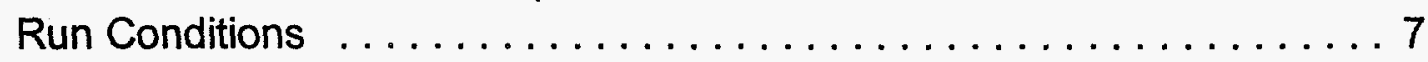

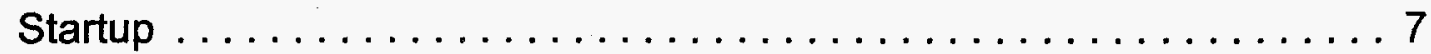

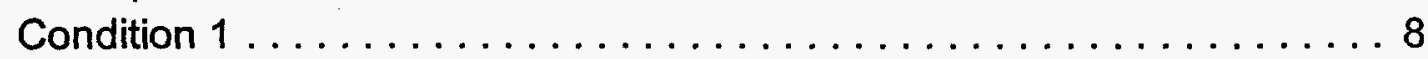

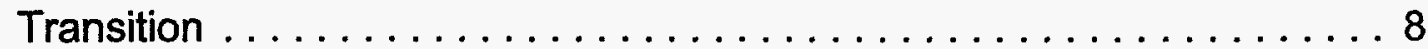

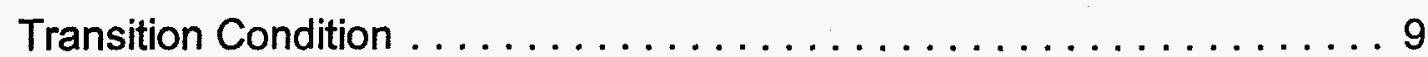

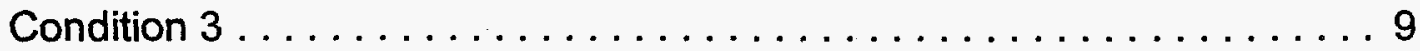

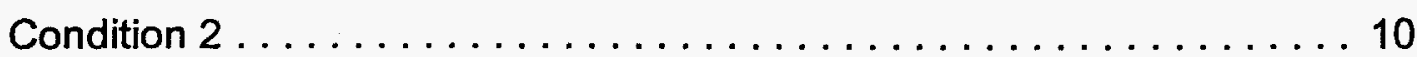

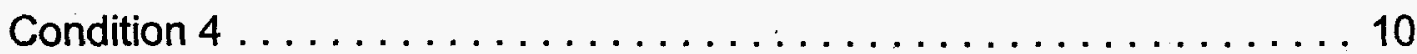

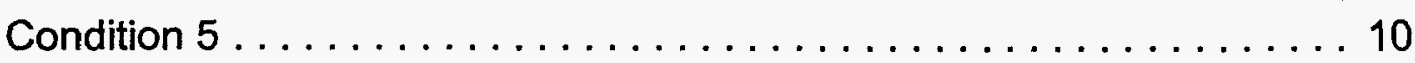

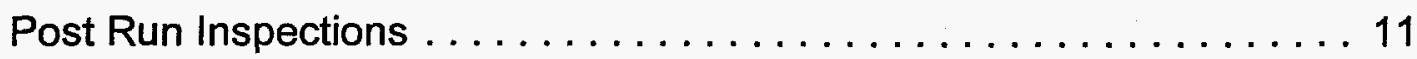

Recommendations ......................... 11 


\section{TABLE OF CONTENTS}

(Continued)

PROCESS PERFORMANCE RESULTS $\ldots \ldots \ldots \ldots \ldots \ldots \ldots \ldots \ldots$

Total Coal (mixed-feed) and $524^{\circ} \mathrm{C}^{+}$Residuum Conversion . . . . . . 13

$\mathrm{C}_{4}-524^{\circ} \mathrm{C}$ Distillate Yield and $524^{\circ} \mathrm{C}^{+}$Residuum Yield . . . . . . . . 14

Distillate Yield and Selectivity ..................... 14

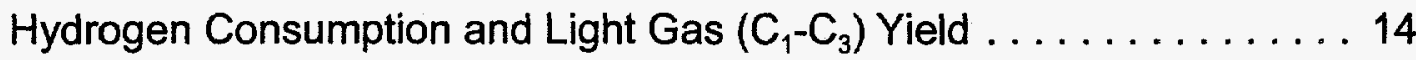

Hydrogen Utilization . . . . . . . . . . . . . . . . . . 15

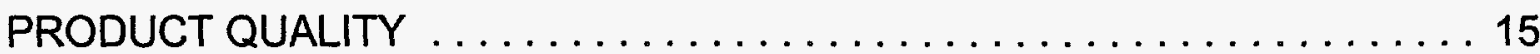

Separator Overhead (SOH) Product .................. 15

Pressure Filter Liquid (PFL) and Pressure Filter Solids (PFS) . . . . . 16

DISCUSSION OF PROCESS PERFORMANCE RESULTS $\ldots \ldots \ldots \ldots \ldots 17$

Effect of HTl's New Dispersed Catalyst and Extinction Recycle . . . . 17

Effect of Feed Type on Combined Processing $\ldots \ldots \ldots \ldots \ldots \ldots 17$

TECHNO-ECONOMIC ASSESSMENT $\ldots \ldots \ldots \ldots \ldots \ldots \ldots \ldots \ldots$

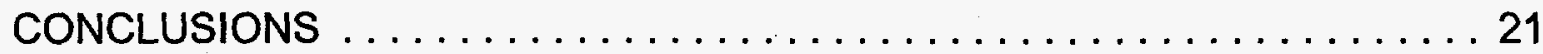

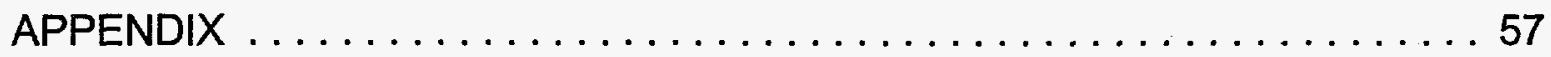

Abbreviation

Daily Unit Material Recovery Balance

Normalized Yields of Gaseous Products

\section{DISCLAIMER}

This report was prepared as an account of work sponsored by an agency of the United States Government. Neither the United States Government nor any agency thereof, nor any of their employees, makes any warranty, express or implied, or assumes any legal liability or responsibility for the accuracy, completeness, or usefulness of any information, apparatus, product, or process disclosed, or represents that its use would not infringe privately owned rights. Reference herein to any specific commercial product, process, or service by trade name, trademark, manufacturer, or otherwise does not necessarily constitute or imply its endorsement, recommendation, or favoring by the United States Government or any agency thereof. The views and opinions of authors expressed herein do not necessarily state or reflect those of the United States Government or any agency thereof. 


\section{LIST OF TABLES}

Table 1.

Table 2.

Table 3.

Table 4.

Table 5.

Table 6.

Table 7.

Table 8.

Table 9.

Table 10.

Table 11.

Table 12.

Table 13.

Table 14.

Table 15.

Table 16.

Table 17.
Run Plan for the Bench Run PB-04 . . . . . . . . . . . . 22

Analysis of Feed Black Thunder mine coal . . . . . . . . 23

Analyses of Heavy Oil, ASR, and Waste Plastics Feed . . . . 24

Analysis of Start-up/Make-up Oil . . . . . . . . . . . 25

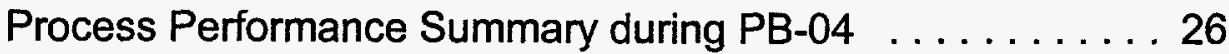

First Stage Separator Overhead (SOH) Properties . . . . . . 27

Second Stage Separator Overhead $(\mathrm{SOH})$ Properties . . . . 28

Pressure Filter Liquid (PFL) Properties . . . . . . . . . . . . . 29

Second Stage Pressure Filter Solids (PFS) Properties . . . . 30

Composite Feed Analysis . . . . . . . . . . . . . . . . 31

Material Balance for Economic Assessment . . . . . . . 32

Hydrogen Balance, Utilities Production, and Thermal

Efficiency ........................... 33

Liquefaction Plant Investment Details . . . . . . . . . . . 34

Total Plant Investment Summary . . . . . . . . . . . . 35

Product Cost Calculation ...................... 36

Breakdown of Equivalent Crude Oil Price .......... 37

Economic Comparisons at Maximum Reactor Throughput . . 38 


\section{LIST OF FIGURES}

Figure 1. Simplified Schematic of HTl's Bench-Scale Unit Configured for Run PB-04 ...................... 39

Figure 2. PB-04: Daily Operating Conditions $\ldots \ldots \ldots \ldots \ldots \ldots \ldots$

Figure 3. PB-04: Daily Material Recovery Balance $\ldots \ldots \ldots \ldots \ldots . \ldots 41$

Figure 4. PB-04: Feed Composition ................ 42

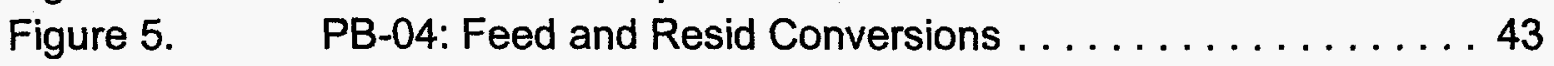

Figure 6. PB-04: $\mathrm{C}_{4}-524^{\circ} \mathrm{C}$ Distillate Yield and $524^{\circ} \mathrm{C}^{+}$Yield . . . . . 44

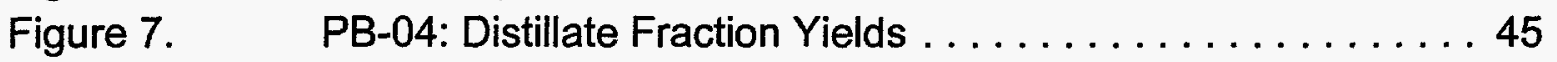

Figure 8. PB-04: Distillate Fraction Selectivity $\ldots \ldots \ldots \ldots \ldots \ldots$

Figure 9. PB-04: Hydrogen Consumption and Light $\mathrm{C}_{1}-\mathrm{C}_{3}$ Gas Yield . . 47

Figure 10. PB-04: Hydrogen Efficiency and $C_{1}-C_{3}$ Gas Selectivity . . . 48

Figure 11. PB-04: Quality of SOH Distillates ............ 49

Figure 12. PB-04: Product $\mathrm{H} / \mathrm{C}$ Ratio $\ldots \ldots \ldots \ldots \ldots \ldots \ldots \ldots \ldots \ldots \ldots \ldots$

Figure 13. PB-04: Solubility of PFL Product $\ldots \ldots \ldots \ldots \ldots \ldots \ldots \ldots$

Figure 14. PB-04: Effect of Dispersed Catalyst and Extinction Recycle

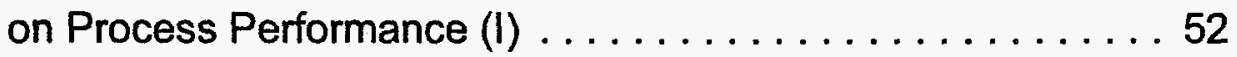

Figure 15. PB-04: Effect of Dispersed Catalyst and Extinction Recycle on Process Performance (I) ................. 53

Figure 16. PB-04: Effect of Feed Type on Process Performance . . . . . 54

Figure 17. PB-04: Economic Effect of ASR Cost $\ldots \ldots \ldots \ldots \ldots 5$

Figure 18. PB-04: Capital Sensitivity ................. 56 


\section{ABSTRACT}

This report presents the results of bench-scale work, Bench Run PB-04, conducted under the DOE Proof of Concept - Bench Option Program in direct coal liquefaction at Hydrocarbon Technologies, Inc. in Lawrenceville, New Jersey. The Bench Run PB-04 was the fifth of the nine runs planned in the POC Bench Option Contract between the U.S. DOE and Hydrocarbon Technologies, Inc. Bench Run PB-04 had multiple goals. These included the evaluation of the effects of dispersed slurry catalyst system on the performance of direct liquefaction of a subbituminous Wyoming Black Thunder mine coal under extinction recycle $\left(454^{\circ} \mathrm{C}+\right.$ recycle) condition; another goal was to investigate the effects of the combined processing of automobile shredder residue (auto-fluff) with coal and other organic waste materials. PB-04 employed a two-stage, back-mixed, slurry reactor system with an interstage $V / L$ separator and an in-line fixed-bed hydrotreater.

The HTl's newly modified P/Fe catalyst was very effective for direct liquefaction and coprocessing of Black Thunder mine subbituminous coal with Hondo resid and autofluff; during 'coal-only' liquefaction mode, over $93 \%$ maf coal conversion was obtained with about $90 \%$ residuum conversion and as high as $67 \%$ light distillate $\left(\mathrm{C}_{4^{-}}\right.$ $975 \mathrm{~F}$ ) yield, while during 'coprocessing' mode of operation, distillate yields varied between 58 and $69 \%$; the residuum conversions varied between 74 and $89 \%$ maf. Overall, it is concluded, based upon the yield data available from PB-04, that autofluff, containing primarily polyurethanes and high impact polystyrene, is not as effective as MSW plastics in improving coal hydroconversion process performance. Auto-fluff did not increase light distillate yields nor decrease light gas make and chemical hydrogen consumption in coal liquefaction, as was observed to occur with MSW plastics. 


\section{EXECUTIVE SUMMARY}

Bench Run PB-04 was the fourth of nine runs planned in the POC Bench Option Contract between the U.S. DOE and Hydrocarbon Technologies, Inc. The primary goal of this bench run was to evaluate the combined processing of automobile shredder residue (ASR) and Hondo VTB resid with Wyoming Black Thunder Mine coal. ASR is essentially the plastics and foam containing material that is recovered from automobiles when they are junked and shredded to remove most of the ferrous and non-ferrous metals. Typically about 600-700 pounds of ASR is recovered from an average-size U.S. automobile. The effects of using ASR, commonly called auto-fluff, in combined processing with coal were studied, along with the usage of MSW plastics, at 20,25 , and $30 \mathrm{w} \%$ of auto-fluff in the combined dry feed. The auto-fluff material was acquired from the Camden Metal \& Recycling Company in New Jersey and was hand-picked to remove as much metal (and other dirt) as possible. The hand-cleaned fluff was found to contain mineral matter (ash) in the range of 14-20 w\%. The auto-fluff was prepared for feeding to the hydroconversion reactors by predissolving it in either Hondo resid or coal-derived recycle solvent.

The bench run was conducted during a 23-day long continuous operation, spanning five operating conditions. The first operating condition, Condition 1, was run in a direct liquefaction or 'coal-only' feed mode and studied the effect of a phosphorous-modified iron catalyst (first used during one operating condition of the Bench Run PB-03) at high feed space velocity and in an all dispersed catalyst mode under extinction recycle $\left(454^{\circ} \mathrm{C}+\right)$ conditions. Condition 2 studied the coprocessing of a heavy petroleum resid, Hondo VTB, with auto-fluff, while Condition 3 evaluated the combined processing of coal, resid, and auto-fluff under similar reaction severity. Condition 4 studied the coprocessing of coal with ASR, while the last condition, Condition 5, studied the coprocessing of coal with auto-fluff and MSW plastics. Bench Run PB-04 was initially scheduled to be a 25-day long operation, but due to feed line plugging problems encountered during Period 23, the run was prematurely shutdown.

Following were the highlights of Bench Run PB-04:

- $\quad H$ TI's newly modified P/Fe catalyst was very effective for direct liquefaction and coprocessing of Black Thunder Mine subbituminous coal with Hondo resid and auto-fluff; during the 'coal-only' liquefaction mode, over $93 \%$ maf coal conversion was obtained with about $90 \%$ residuum conversion and as high as $67 \%$ light distillate $\left(\mathrm{C}_{4}-975 \mathrm{~F}\right)$ yield. During the 'coprocessing' mode of operation, distillate yields varied between 58 and $69 \%$; and residuum conversions varied between 74 and $89 \%$ maf. 
- The combined processing of coal with Hondo resid and auto-fluff, carried out for the first time at $\mathrm{HTI}$, resulted in about $84 \%$ residuum conversion and over $67 \%$ light distillate yield.

- When coprocessing a mixture of $75 \%$ coal and $25 \%$ auto-fluff, the total feed conversion, based upon quinoline solubility of the products, decreased; there was also a substantial drop in resid conversion and light distillate yield. When part of the auto-fluff was replaced by simulated MSW plastics, conversions and distillate yield increased markedly. Chemical hydrogen consumption decreased with MSW plastics in the feed.

- Based upon the yield data available from PB-04, it is concluded that auto-fluff, containing primarily polyurethanes and high impact polystyrene, is not as effective as MSW plastics in improving coal hydroconversion process performance. Auto-fluff did not increase light distillate yield nor decrease light gas make and chemical hydrogen consumption, as was osbserved to occur with MSW plastics.

\section{BACKGROUND, OBJECTIVE, AND SCOPE OF WORK}

The POC Bench Option Project (PB-Series) is geared to evaluate different novel processing concepts in catalytic coal liquefaction and coprocessing of organic wastes such as plastics, heavy resids, waste oils, and ligno-cellulose wastes with coal. The long-term performance data at the bench scale of operations ( $30 \mathrm{~kg} / \mathrm{day})$ will be used eventually to complement the larger scale process demonstration "Proof-of-Concept" studies for the U.S. DOE. The new ideas being explored in this program include using novel dispersed slurry catalysts, combinations of dispersed and supported catalysts (hybrid mode), coprocessing of coal with waste plastics, low quality resids, waste oils, and ligno-cellulosic wastes etc. As the POC Bench Option Program succeeded a recently completed Catalytic Multi-Stage Liquefaction (CMSL) Project, one of the primary objectives of the third bench run, $\mathrm{PB}-03$, was to investigate the impact of varying dispersed catalyst loadings on the process performance in direct liquefaction of subbituminous Black Thunder Mine coal using dispersed catalysts only in the hydroconversion reactors. Bench Run PB-04 was then carried out for 23 operating days, spanning five process conditions designed to evaluate the effects of using an improved HTI iron slurry catalyst (phosphorous modified) and to study the combined processing of auto-shredder residue with coal and heavy residua. The following were the specific technical objectives: 
- To study the activity of HTl's newly improved, phosphorous-modified, iron gel catalyst for direct liquefaction of Black Thunder Mine coal at high space velocity in an all-dispersed catalyst mode and under extinction recycle condition.

- To study the combined processing, under coal liquefaction conditions, of autoshredder residue material with:
A. Subbituminous Coal
B. Heavy Petroleum Resid
C. Mixture of Coal and Resid
D. Mixture of Coal and MSW Plastics

The detailed run plan for PB-04 is shown in Table 1. The space velocity of the total dry feed was maintained around $640 \mathrm{~kg} / \mathrm{h} / \mathrm{m}^{3}$ reactor volume, while the reactor temperatures were maintained at 440 and $449^{\circ} \mathrm{C}$, for the first and the second stage reactors. respectively. The in-line hydrotreater was maintained at $379^{\circ} \mathrm{C}$, while the amount of dispersed catalysts in the fresh feed was set at $1000 \mathrm{ppm}$ iron, $100 \mathrm{ppm}$ phosphorous, and $50 \mathrm{ppm}$ molybdenum (Molyvan-A). The percentage of auto-fluff in the combined feed was varied between 20 and 30 w\% over the course of the run.

\section{SYSTEM CONFIGURATION}

Run PB-04 was conducted in HTl's Unit 227, with an interstage product separator and an in-line hydrotreating unit (HTU). The first stage separator overhead oil and process knockouts were fed to the in-line HTU along with a direct feed of the 0-1 separator overheads. The 0-1 separator bottoms were sent to a flash vessel, O-3, and then to a lowpressure receiver, 0-6 (Figure 1 shows the simplified schematic of the unit configuration). The 0-6 bottoms material was sent to an off-line pressure filter for the recovery of recycle PFL. In order to be able to achieve extinction recycle $\left(454^{\circ} \mathrm{C}+\right.$ recycle), the whole PFL was vacuum distilled to separate the $454^{\circ} \mathrm{C}+$ material (VSB) for recycle. The lighter VSOH material was partly blended with the 0-6 bottoms (filter feed) to speed up the filtration, while the remaining part of the VSOH was treated as the net product. Two independent gas feed and discharge systems are required to handle the gas in the two-stage-interstage separation configuration. 


\section{MATERIALS USED}

\section{Feeds}

Wyoming Black Thunder mine coal, the same coal that was used in the PDU 260-005 operations, was also used for the PB-04 (227-95) Bench Run; the other feeds included an ASR material from Camden Metal \& Recycling, NJ, California Hondo Resid VTB, and simulated MSW plastics. The analytical data on the feeds are shown in Tables 2 through 4.

\section{Start-up and Make-up Oil}

L-814

\section{Catalysts}

Hydrotreater: $\quad$ Criterion C-411 Trilobe

K-1 \& K-2 : $\quad$ Dispersed iron (P-modified) and molybdenum catalysts.

\section{INTERSTAGE (REACTOR K-1) SLURRY SAMPLES}

Five interstage (reactor K-1) slurry samples were planned, one each for Conditions 1 , $2,3,4$, and 5 . These samples were to be collected immediately after the completion of each of the indicated work-up periods. In reality, only one interstage sample was collected, representing the first process condition. 


\section{SUMMARY OF OPERATIONS}

\section{Unit Modification and Configuration}

For Run PB-04, the 227 Unit was set up to process subbituminous coal, petroleum resid, waste plastics, and auto salvage residue using two 2000 -cc reactor stages with interstage product separation. Neither stage contained supported catalyst; the only catalyst used was slurry catalyst mixed with the feed. This run also employed the in-line hydrotreater and a reactor preheater coil.

Premixed feed slurry was charged to the feed tank (P-2) every six hours and pumped to the backmixed first stage reactor $(\mathrm{K}-1)$ via a short-residence-time (approximately 5 minutes) preheater coil. The effluent from K-1 was separated in the interstage hot separator $(0-1 \mathrm{~A})$, which removed lighter liquids and gases before the feed entered the backmixed second stage reactor (K-2). The products from $\mathrm{K}-2$ were separated using a hot separator (O-1). The $\mathrm{O}-1$ bottoms were depressurized and sent to the bottoms flash vessel (O-3), and the $0-3$ bottoms were sent to the bottoms receiver $(0-6)$. Overheads from $0-1$, combined with the overhead liquids from $0-1 A$ and $0-6$, flowed through the inline hydrotreater (HTU) and then through a cold separator (O-2). The separator bottoms from O-6 were sent to a batch pressure filter. The pressure filter liquid (PFL) was sent to a batch vacuum still, and the pressure filter cake (PFC) was sent to a toluene extraction unit to produce extracted oil (EO) and extracted cake (ES). The recycle streams for the first ten periods were all of the $454^{\circ} \mathrm{C}+\mathrm{PFL}$ (VSB) and enough $454^{\circ} \mathrm{C}$ - PFL (VSO) to make the total specified recycle rate.

\section{Dispersed Catalyst Preparation}

Gel forms of phosphorous-modified iron catalyst (L-870, L-871, L-872, L-874, L-877, and $\mathrm{L}-878$ ) were prepared in the Myers mixer according to a proprietary procedure.

\section{Auto Shredder Residue Preparation}

Auto Shredder Residue (ASR), the shredded remainder of automobiles after the ferrous and most of the non-ferrous metal has been removed, were obtained from Camden Iron and Metal Co. in Camden, N.J. The ASR was hand-sorted to remove metal pieces and other large inorganic components. 
The first $400 \mathrm{lbs}$ of hand-sorted ASR were mixed with $300 \mathrm{lbs}$ of Hondo resid at $480^{\circ} \mathrm{F}$ in the 260 Unit O-60 tank, and the resid and dissolved plastics were drawn off the top. This ASR solution, L-892, contained 40\% ASR and was used in Conditions 2 and 3 . For Conditions 4 and 5, the hand-sorted ASR was dissolved in the unit derived recycle material (PFL). This dissolution utilized ratios of 1.5 parts PFL to 1 part ASR. However, this 1.5:1 ratio was found to produce a slurry that could not be removed from the mix tank. A 2:1 PFL to ASR ratio was successfully used.

\section{Run Conditions}

Run PB-04 included five different conditions. The only variable was the feed composition. The reactor temperatures at the 42 -inch level were $443^{\circ} \mathrm{C}(\mathrm{K}-1)$ and $452{ }^{\circ} \mathrm{C}(\mathrm{K}-2)$, and the back pressures were $2,650 \mathrm{psig}(\mathrm{K}-1)$ and $2500 \mathrm{psig}(\mathrm{K}-2)$ throughout the run.

\section{Startup}

Startup consisted of establishing the proper flows of oil and gases, presulfiding the catalyst in the fixed-bed hydrotreater, setting vessel temperatures, testing the first stage sample system, and increasing the reactor temperatures to $413^{\circ} \mathrm{C}$. Filtered L-814, heavy gas oil, was used as a startup oil for this run. The recycle material generated during the reactor heat-up period was used to slurry the coal at the beginning of Period 1.

The startup was interrupted by a hard carbonaceous plug in the top of the K-1 riser tube. The reactor and top head assembly were clean and clear, but there was heavy material in the preheater coil and first stage sample system valves SV-10 and SV-11 (for flow through the sample cylinder), which were cleaned before resuming the startup. Startup resumed at 0200 Sunday, June.

After restarting oil flow, a 50+ psi pressure drop developed in K-2. The restriction was cleared by increasing the interstage pressure and decreasing the back pressure. An experimental diamond coated " $M$ " size trim was placed in service in the O-1A level control valve at about 1010 hours June. The trim did not allow the valve to open sufficiently to pass $0-1 \mathrm{~A}$ bottoms. The valve was heated to $232^{\circ} \mathrm{C}$ and placed online. Once again the valve could not control the level. It was replaced with a standard tungsten carbide trim. This diamond coated trim was tried again in Period 4, but the valve once again could not control the level.

A first stage sample was taken on Sunday, June 6. This procedure was followed to ensure that the sampling system was operational. 


\section{Condition 1 (Periods 1 through 6)}

Period 1 started with the introduction of coal feed at 0400 hours June 3, 1996. (Each 24 hour period started and ended at 0400 hours.) The feed rate and reactor temperatures were gradually increased, reaching full coal rate of $1465 \mathrm{~g} / \mathrm{h}$ at 1600 hours and Condition 1 reactor temperatures, at the 42 " level, of $443{ }^{\circ} \mathrm{C}(\mathrm{K}-1)$ and $452{ }^{\circ} \mathrm{C}(\mathrm{K}-2)$ at 0800 hours Period 2. There were some restrictions in the O-1A and O-3 level control valves, which temporarily prevented them from passing slurry. The experimental diamond-coated trim was tested in the $0-1$ level control valve during Period 4 , but it again failed to open sufficiently.

The interstage pressure was maintained at $2650 \mathrm{psig}$, because the originally specified pressure of $2550 \mathrm{psig}$ ( $50 \mathrm{psi}$ DP) did not allow enough material to pass through the 0-1A control valve. A middle electrical winding had a break in it that was repaired at the beginning of Period 2. In Period 4 the O-1A level control valve did not pass enough material unless it was operated manually. After the pressure drop across it was temporarily increased to $350 \mathrm{psi}$, it functioned better.

In each of Periods 3 and 5 the water pump for O-1A was off-line for about 5 hours. The checks were cleaned, and it was repacked. The feed pump stopped pumping 7 times during Periods 5 and 6 , and the circulating pump leaked about $1100 \mathrm{~g}$. The HTU pump was off for 2 hours, while it was repaired. In Period 4 the pressure filtrations began taking more than 2 hours, even though the filter feed was divided between two filters. VSOH was used as diluent at ratios of $1: 10$ to $1: 2$ when it was available, but the filtrations were still not able to keep up with the 0-6 bottoms production. O-6 bottoms were recycled directly to the feed during periods 5 and 6 . The third, 18-inch, pressure filter was also used, but sometimes no liquid would pass through any of the filters. A $373 \mathrm{~g}$ first stage slurry sample was successfully obtained at the end of Condition 1 .

\section{Transition (Periods 7 through 8A)}

In Condition 2 the fresh feed was changed to $1318 \mathrm{~g} / \mathrm{h} \mathrm{L-892}(527 \mathrm{~g} / \mathrm{h}$ ASR plus $791 \mathrm{~g} / \mathrm{h}$ Hondo resid). The total VSB-plus-VSO recycle was $1318 \mathrm{~g} / \mathrm{h}$. Feed problems were prevalent during Period 7 . There was a large loss through the circulating pump packing. Later, an increased pressure drop in the feed line preceded the failure of the $\mathrm{J}-2$ charge pump checks to hold. The J-1 pump also did not work. VSO was charged with the buffer pumps while the feed was out for 5 hours. Both pumps were down again for $11 / 2$ hours until flow of L-814 was achieved. The pressure drop in the feed line then temporarily increased to 200 psi. 
During Period 7B, the feed tank (P-2) was drained and the contents replaced with the startup oil (L-814). The unit remained on wash until 0400 hours Period $8 \mathrm{~A}$. At that time, the feed composition was again at Condition 1 . The objective was to put the unit on coal feed. Condition 3 feed blend (containing L-892) was initiated at about 1600 hours initiated. Condition 2 was deferred until later in the run.

\section{Transition Condition (Periods 8B through 9)}

Starting with Condition 1 feed rates, the feed rate of L-892 was increased to $879 \mathrm{~g} / \mathrm{h}$ and the feed rate of coal was decreased to $488 \mathrm{~g} / \mathrm{h}$ over a period of 24 hours.

Feed outages became progressively longer in Period 9 . VSO buffer feed to both reactors was implemented to maintain flow, and later the feed was replaced with L-814 makeup oil. Twice the pressure drop across $\mathrm{K}-1$ reached 50 psi. Condition 3 feed blend was replaced with Condition 1 feed at about 0030 hours June 11, Period 9B.

\section{Condition 3 (Periods 10 through 12)}

The fresh feed was again returned to the Condition 1 coal-only specification until 1600 hours Period 10 when L-892 feed was resumed at $693 \mathrm{~g} / \mathrm{h}$. The coal rate became $693 \mathrm{~g} / \mathrm{h}$ and the recycle rate became $554 \mathrm{~g} / \mathrm{h}$ PFL and $831 \mathrm{~g} / \mathrm{h}$ 0-6 bottoms. Two power interruptions due to passing storms resulted in a loss of the hydrogen compressor, P-7 circulation pump and the computer system. All affected equipment was brought back online with no effect to the unit.

A 600 psi unit pressure loss was experienced in Period 10 when a block valve failed when attempting to clear the $\mathrm{K}-1$ left side recycle pump. A temperature excursion $\left(870^{\circ} \mathrm{F}\right.$ max temperature) was experienced in K-2. No lasting effects were noted. The first stage overall differential pressure and $\mathrm{K}-1$ inlet pressure issues occurred during Period 12. The differential pressure oscillated between 30 and 50 psi. The inlet pressure rose to above $3025 \mathrm{psig}$, which stopped hydrogen flow to the first stage. The back pressure was lowered in an attempt to relieve the plug. At a differential pressure of $688 \mathrm{psi}(3043-2355 \mathrm{psig})$ the plug broke. 


\section{Condition 2 (Periods 13-16)}

A first stage sample was successfully taken at the beginning of Period 13 . Condition 2 feed blend was once again fed to the unit. The first stage inlet pressure again exhibited a rise to over 2800 psig. Lowering the back pressure had no effect. The hydrogen flow was subsequently switched from the right side to the left side check. The inlet pressure returned to normal. At the end of Period 15A, feed was switched to wash oil. This action was taken due to the inlet pressure oscillations and high K-1 differential pressure. At the end of Period 15B, hydrogen feed to K-1 was switched from the now plugged right side check to the third and last position. Unit instability continued during Period 16. In addition, the TNPS pump began to shutdown on high pressure indicating that the TNPS line was plugging.

\section{Condition 4 (Periods 17-20)}

The transition from unit wash to Condition 4 was to occur during periods 17 and 18 . Period 17 would initiate coal feed to the unit. Period 18 would see a transition to using L-893 (ASR and process derived oil). However, due to issues with removing the L-893 Blend \#1 from the dissolution tank, L-893 was not used until period 20. Throughout Period 19 efforts were directed to removing the L-893 blend \#1 from the tank. The original 1.5:1 PFL:ASR ratio produced a material that was so thick it would not drain from the tank even at $316+$ ${ }^{\circ} \mathrm{C}$. After the material was diluted (ultimately using a 2:1 ratio), it was removed from the tank. The second and all subsequent blends were made using a $2: 1$ ratio and $288^{\circ} \mathrm{C}$ as a minimum dissolution temperature. Handling issues required that once the blend was removed from the dissolution tank, the material had to be frozen and then pulverized to render it in an easily handled form. Elemental sulfur addition commenced in Period 19 due to the plugging of the TNPS line.

\section{Condition 5 (Periods 21 through 23)}

During Periods 20,21 , and $22 \mathrm{~L}-893$ Blend \#3, \#4, and \#5 were made. The total amounts produced for all the blends after freezing and pulverizing were:

Blend \#1 $22.2 \mathrm{~kg}$

Blend \#2 $24.9 \mathrm{~kg}$

Blend \#3 $26.3 \mathrm{~kg}$

Blend \#4 $22.7 \mathrm{~kg}$

Blend \#5 $23.1 \mathrm{~kg}$ 
During Period 20 a third power failure due to storms occurred: This power outage combined with a power supply failure, resulted in a loss of all computer based process controls for Unit 227. K-2 temperatures fell to $377^{\circ} \mathrm{C}$ before control was restored. Period 21 saw the fourth and last power outage experienced during the run. This momentary outage only caused the computer to go down and then come back online. K-1 inlet pressure and feed pump issues continued throughout Condition 5. Period 22 saw the addition of mixed plastics to the feed blend. At 0200 hours Period 23B, J-2 feed pump went off line due to high discharge pressure. The feed line to $\mathrm{K}-1$ was pugged and could not be cleared. Unit shutdown commenced.

\title{
Post Run Inspections
}

The unit was cooled and depressurized, ready for turnaround, by 0800 , June 28 . The following lines and section were plugged:

\author{
Feed line to the coil \\ Coil \\ Two gas checks and lines \\ TNPS injection line
}

$\mathrm{P}-2$, the circulation lines, and lines to the feed pumps were all found to be dirty, plugged or restricted. The circulation lines required total replacement. The K-1 thermowell broke when the top head was removed from the reactor. Both $\mathrm{K}-1$ and $\mathrm{K}-2$ needed to be drilled out and flushed clean. A total of $709 \mathrm{~g}$ (net) of catalyst were removed from the hydrotreater.

\section{Recommendations}

Further dissolution work is needed to determine the optimum conditions for dissolving the Auto Shredder Residue (ASR) with process derived oils. It appears that a ratio of 2 parts oil to 1 part ASR is the minimum needed for dissolution. Feed tank temperatures and feed viscosity must be closely monitored when working with ASR. Diluting the feed with an appropriate oil may prove beneficial when feed pump problems begin. 
Table A. Run PB-04 Operations-status-classification Chronology

Operations

\begin{tabular}{|c|c|c|c|c|c|}
\hline \multirow{2}{*}{$\begin{array}{c}\text { Classification } \\
\text { I.D. } \\
\end{array}$} & \multicolumn{2}{|c|}{ Start } & \multicolumn{2}{|c|}{ End } & \multirow{2}{*}{$\begin{array}{c}\begin{array}{c}\text { Duration } \\
\text { Hours }\end{array} \\
\end{array}$} \\
\hline & Time & Date & Time & Date & \\
\hline S/U & 1100 & $5 / 31 / 96$ & 1100 & $6 / 1$ & 24 \\
\hline S/D & 1100 & $6 / 1$ & 1100 & $6 / 1$ & 0 \\
\hline$D / T$ & 1100 & $6 / 1$ & 0200 & $6 / 2$ & 15 \\
\hline$S / U$ & 0200 & $6 / 2$ & 0400 & $6 / 3$ & 26 \\
\hline $1-23$ & 0400 & $6 / 3$ & 0200 & $6 / 26$ & 550 \\
\hline S/D & 0200 & $6 / 26$ & 0000 & $6 / 28$ & 46 \\
\hline
\end{tabular}

\section{Table B. On-line Time and down Time for Run PB-04}

Time of Intermediate

Time of Initial S/Ds \& S/Us, Hours Total On-

S/U \& Final

S/D. Hours

70

(No. of Int. S/D-S/U) Line Time, Down-Time,

On-Line

$\frac{\text { Pairs) }}{26(1)} \frac{\text { Hours }}{646} \frac{\text { Hours }}{15} \frac{\text { Efficiency, \% }}{97.7 \%}$

Definitions:

$S / U=$

$S / D=$

Run-Periods $=$

On-Line Time $=$

Down-Time $=$

On-Line Efficiency $=$
Startup. Time between gas flow initiation and feedstock cut-in during which unit temperatures and/or pressures are being increased.

Shutdown. Time between feedstock cut-out and liquid flow termination during which unit temperatures and/or pressures are being decreased.

Time during which the unit is at run conditions and the operations is identified with a Period number.

The sum of S/Us, S/Ds, and Run-Periods.

The time during which gases and liquids are not being charged to the unit. This is the same as the time between an intermediate shutdown and startup.

On-Line Time / (On-line Time + Down-Time) 


\section{OPERATING CONDITIONS AND MATERIAL RECOVERY BALANCES}

The presence of auto-fluff in the combined feed resulted in repeated feed pump problems, which were successfully overcome by HTI's operations until the very end (Period 23). An average material recovery balance (the daily material balance summary is attached in the Appendix) of about 101.4 W\% was obtained (Figure 3) for the entire Bench Run PB-04. The operating summary and the process performance of individual periods during PB-04 are shown in Table 5. Figure 2 shows the operating conditions during PB-04 in terms of feed space velocities and reactor temperatures. As shown in Figure 2, the reactor temperatures and feed space velocities during Conditions 1 through 5 were uniform except for the periods that encountered operational problems or difficulties. The overall feed composition for the individual operating conditions of the Run PB-04 is depicted in Figure 4.

\section{PROCESS PERFORMANCE RESULTS}

The conversions and yields of different products, process performance, and product quality for PB-04 are addressed in this section. The calculation of daily material recovery balances, coal conversions, normalized product yields, and other process performancerelated indicators were carried out using programs available in the microvax database (some programs were also modified as per the requirement of the process configuration for PB-04, for example, handling of three independent gas streams for material balance). The overall process performance during PB- 04 is summarized in Table 5 and depicted in Figures 5 through 10 and is discussed in detail in the following sections.

\section{Total Coal (mixed-feed) and $524^{\circ} \mathrm{C}^{+}$Residuum Conversion}

Typical combined feed conversions (based on the solubility of pressure filter solids in quinoline and expressed on an $\mathrm{SO}_{3}$-free basis) obtained during equilibrated periods of different conditions of PB-04 are shown in Figure 5. The feed conversions (W\% maf feed) varied between about 90 and $96 \%$ throughout the course of the run. The highest feed conversion of over $96 \mathrm{w} \%$ maf feed was obtained with a feed consisting of $70 \mathrm{w} \%$ Hondo resid and $30 \mathrm{w} \%$ ASR. The lowest conversion of close to $90 \mathrm{w} \%$ was obtained with a combination of $75 \mathrm{w} \%$ coal and $25 \mathrm{w} \%$ ASR fed during Condition 4 . The conversion of $524^{\circ} \mathrm{C}+$ residuum from feed is also plotted in Figure 5 . The residuum conversion varied between about 72 and $89 \mathrm{~W} \%$ (maf feed). The highest resid conversion was obtained during Condition 1 with 'coal-only' feed and practicing the extinction recycle mode of operation. Based upon the low values of residuum conversions $(72-84 \mathrm{w} \%)$ obtained during 
the run conditions employing ASR in the combined feed, it is speculated that the ASR used during the run PB-04 contained polymers/plastics which are more difficult to convert to $524^{\circ} \mathrm{C}$ - material than those present in the MSW plastics.

\section{$\mathrm{C}_{4}-524^{\circ} \mathrm{C}$ Distillate and $524^{\circ} \mathrm{C}+$ Residuum Yields}

Distillate yields and $524^{\circ} \mathrm{C}+$ residuum yields (includes the unconverted resid material in the feed) are shown in Figure 6 . The distillate yields varied between about 57 and 69 W\% maf combined feed. During the first 'coal-only' feed condition, studying the effects of phosphorous-modified iron dispersed catalyst, a high distillate yield of over $67 \mathrm{~W} \%$ maf was obtained. Similar to the effect of ASR on the overall residuum conversion levels, it was found that the presence of ASR did not at all help the process performance from the standpoint of achieving high distillate yields; rather, the yields dropped a little (as compared to the conditions which did not employ ASR in the feed) during the conditions employing ASR with coal or with a mixture of coal and Hondo resid. The residuum yields were between 4-18 W\% maf and followed a similar variation trend as the light distillate yields.

\section{Distillate Yield/Selectivity}

The yields of distillate fractions such as naphtha (IBP- $\left.177^{\circ} \mathrm{C}\right)$, middle distillate $\left(177-343^{\circ} \mathrm{C}\right)$, and heavy distillate $\left(343^{\circ} \mathrm{C}+\right)$ are shown in Figure 7 . The numbers plotted in this figure, converted to a selectivity basis, are shown in Figure 8 . The light fractions, namely naphtha and middle distillate, were about the same during Conditions 1 through 3 ; these fractions decreased during Conditions 4 and 5 when ASR was coprocessed with coal and mixtures of coal and MSW plastics. That highest selectivity to heavy distillate $\left(343^{\circ} \mathrm{C}+\right)$ was obtained during Condition 4 is noteworthy.

\section{Hydrogen Consumption and Light Gas $\left(C_{1}-C_{3}\right)$ Yield}

Hydrogen consumption (Figure 9), based upon maf feed, varied from 4.0 to $7.2 \mathrm{~W} \%$. In general, chemical hydrogen consumption during PB-04 tended to be on the low side, primarily because no supported catalyst was used, and space velocities were high; thus, the operating severity was on the low side. The hydrotreater, due to some fouling problems, was not functioning to its full capacity. As was the case with MSW plastics during the previous bench runs, it was noted during PB-04 that ASR material in the combined feed with coal resulted in lower gas production and lower hydrogen consumption. 


\section{Hydrogen Utilization}

Hydrogen utilization during coal conversion is characterized by two indicators: hydrogen efficiency and $\mathrm{C}_{1}-\mathrm{C}_{3}$ gas selectivity. The former is defined as the amount of $\mathrm{C}_{4}-524^{\circ} \mathrm{C}$ distillates obtained per unit weight of hydrogen consumed, while the latter is the amount of light hydrocarbon gases produced per unit weight of distillates. As shown in Figure 10, hydrogen efficiency varied between about 9 to $15 \%$. The lowest hydrogen efficiency of $9 \%$ was obtained, as expected, with the 'coal-only' feed condition; the hydrogen efficiency was not any different for Condition 4, which employed a combined feed of $75 \mathrm{w} \%$ coal and $25 \mathrm{w} \%$ ASR material. This is due to the fact that even though the presence of ASR in the combined feed had lowered the hydrogen consumption, it had lowered the light distillate yield as well. The last condition, Condition 5, with MSW plastics in the combined feed resulted in the highest hydrogen efficiency.

\section{PRODUCT QUALITY}

Different product fractions (product gases, $\mathrm{SOH}$-first and second stage products, $\mathrm{PFL}$, and PFS) from Work-up Periods 5, 12, 15, 21, and 23 were analyzed in detail. These analyses are listed in Tables 6 through 9.

\section{Separator Overhead Product (SOH)}

The $\mathrm{SOH}$ oil stream represents the net light distillate (IBP- $343^{\circ} \mathrm{C}$ ) from PB-04. While the hydrotreater unit was on-line during the run, it is believed, based upon the heteroatom levels of the second stage separator overhead oil product, that the in-line HTU was not functioning to its full capacity, probably due to some fouling or catalyst contamination. The properties of $\mathrm{SOH}$ oil (from the first and the second stage separators) for the work-up periods are shown in Tables 6 and 7 . The second stage SOH oils had a typical boiling range of $50-380^{\circ} \mathrm{C}$. The API gravities were high (> 35), and $\mathrm{H} / \mathrm{C}$ atomic ratios were also high (>1.80), especially during the early operating periods when the HTU was functioning better than during the later conditions. The first stage separator overhead product oils had inferior properties compared to the second stage overhead material, an indication that the second stage hydroconversion reactor and the in-line HTU were contributing to quality improvement in the $\mathrm{SOH}$ oil. The nitrogen and sulfur contents were typically high during the run PB-04 : initially around 1000 ppm and later, around $2000 \mathrm{ppm}$. The quality of SOH process distillates, in terms of heteroatoms contents and $\mathrm{H} / \mathrm{C}$ ratios, is depicted in Figures 11 and 12. 


\section{Pressure Filter Liquid (PFL) and Pressure Filter Solids (PFS)}

The separator bottoms $\left(\mathrm{O}_{-6}\right)$ go through pressure filtrations for separation of solids from heavy liquid product and recycle oil. The oil, called pressure filter liquid (PFL), is usually heavier than $343^{\circ} \mathrm{C}$ boiling point and contains the unreacted heavy residuum material to a varying degree. Pressure filter operation, which did not proceed smoothly during some of the previous bench runs in this program, was aided during PB-04 by the addition of a light $\mathrm{VSOH}\left(454^{\circ} \mathrm{C}\right.$-) material (derived from the vacuum distillation of the PFL itself) to the filter feed. The oil-containing solids from filtration, PFS, are normally extracted with toluene for oil recovery, and the oil-free solids are then used for determining the extent of coal or total feed conversion based upon the solubility of the PFS material in a solvent such as quinoline. The detailed analyses of the PFL and PFS streams from PB-04 are listed in Tables 8 and 9 . The PFL API gravity was low $(<5.0)$ for all the conditions, while the resid content of the PFL was between 34-42 W\%, depending upon the type of feed used. The $\mathrm{H} / \mathrm{C}$ ratio, also shown in Figure 12, was typically between 1.0 and 1.3. The toluene and cyclohexane insolubles from the PFL are listed in Table 8 and plotted in Figure 13. The highest insoluble numbers resulted for conditions employing ASR material in combined feed with coal and/or coal and MSW plastics. The pressure filter solids, on the other hand, typically had an $\mathrm{H} / \mathrm{C}$ ratio of about 0.85 and quinoline insolubles of between $50-62 \mathrm{w} \%$ (as shown in Table 9). 


\section{DISCUSSION OF PROCESS PERFORMANCE RESULTS}

\section{Effects of HTI's New Dispersed Catalyst and Extinction Recycle Mode of Operation:}

One of the primary objectives of Bench Run PB-03 was to study the effect of HTl's newly modified iron-based dispersed slurry catalyst on direct liquefaction of subbituminous coal, especially under extinction recycle. The new catalyst was a phosphorous-modified, ironbased, gel catalyst. This catalyst was tested for direct liquefaction for the first time at $\mathrm{HTI}$ during the previous bench run (PB-03). With $100 \mathrm{ppm}$ of phosphorous and $1000 \mathrm{ppm}$ of iron in the fresh feed, successful results were obtained. Overall process performance was better when the phosphorous-modified catalyst was used. Coal conversion, resid conversion, and distillate yields all increased with phosphorous-promotion of the iron catalyst; the gas yields increased slightly, while hydrogen consumption went up a notch. The effects of phosphorous were seen even better during the first condition of PB-04, when extinction recycle was practiced.

Figures 14 and 15 depict the activity enhancement of phosphorous upon HTI's iron gel catalyst. P-modified iron catalyst results in improved performance levels, especially when used with extinction recycle.

\section{Effects of Feed Type on Combined Processing Performance:}

The coprocessing of auto-fluff or ASR with coal and/or petroleum resid was carried out for the first time at $\mathrm{HTI}$ during Bench Run PB-04. It was expected that, because plastics/polymers are the primary constituents of the organic portion of the ASR, ASR would behave similarly to MSW plastics during combined processing with coal and/or resid. The ASR material that was employed for run PB-04 was highly heterogeneous, and samples taken at different times from the source ASR were found to have ash contents varying between $14-20 \mathrm{w} \%$. This material needed to be hand-cleaned and predissolved in either Hondo resid or coal-derived solvent to be used as feed during the run. In general, it was found that ASR did not have a positive influence on coal or heavy oil hydroconversion as was observed earlier with MSW plastics (Figrue16). Similar to the MSW plastics, ASR material reduced light gas formation and chemical hydrogen consumption; unlike MSW, it did not boost resid conversion or distillate yields. It is speculated that the types of polymers/plastics present in the auto-fluff (e.g., high impact polystyrene, a cross-linked polymer) are more difficult to convert to liquids than the polymers in MSW plastics. A more detailed analysis of the ASR material is, therefore, needed to determine the type and amount of individual polymers present so that either 
reaction conditions can be tailored for achieving high conversions or unreactive polymers can be removed. 


\section{TECHNO-ECONOMIC ASSESSMENT}

Feed to Bench Run PB-04 was automobile shredder residue (ASR) in combination with coal, residual oil and plastics. The run featured an interstage separator and in-line hydrotreater and used dispersed molybdenum, iron and phosphorus catalysts.

The feed compositions are presented in Table 10 for the periods analyzed in this assessment of the run. Comparison is shown to a base case with supported catalyst, at nearly the same space velocity but at substantially lower reactor temperature. This base case is the same as presented in the previous PB run reports. Table 11 presents material balances. Liquids production in coal-only operation was outstanding, being the highest observed to date in the PB-series of runs. With ASR, the liquid yield decreased, especially in Period 21 with coal and ASR feed. Table 12 summarizes hydrogen balances, utilities production and thermal efficiencies for the run conditions analyzed. Note that for all PB-4 conditions except with coal only operation, over 60 percent of the hydrogen is produced by partial oxidation.

Liquefaction plant investment details are listed in Table 13, showing little difference between the PB-4 run conditions except in Period 14/15 with Oil/ASR feed. Except for this period, the costs are 5 to 12 percent higher than the base case, because of the higher reactor costs necessitated by the increased gas yields and by the lower space velocities. The cost of compressors and the hydrogen purification units are all higher than the base case due to the higher gas yields. Total plant investment costs are shown in Table 14. Higher gas yields in all the PB-4 periods account for the increased treating costs, compared to the base case. Note that costs have been included for ASR preparation. These were developed from a detailed equipment sizing estimate and costing. Operation with Oil/ASR is substantially below the others on a daily barrel basis, while the coal/ASR is considerably above the others due to the poor distillate yield observed.

Economics are summarized in Table 15, and the breakdown of the equivalent crude oil price is shown in Table 16. Except for Period 21, all the periods investigated showed better economics than the base case. The equivalent crude oil price for coal-only operation is below $\$ 30 / B$ for the first time in the PB-series of runs. Figure 17 presents the economic effect of ASR cost, and shows that above $\$ 5-12 /$ Ton, use of ASR is not economically justified, based on the results of the run. Figure 18 is the capital sensitivity of selected periods. With ASR in the feed the plant cost is more sensitive to investment cost increase than with coal-only operation (Period 5). In summary, results of the technical assessment of PB-4 show that use of Automobile Shredder Residue is economically justified when no charge is taken for this feed. Increased gas yields account for increased investment costs, 
compared to the base case. The addition of phosphorus, as previously found, is economically beneficial, especially in coal-only operation. 


\section{CONCLUSIONS}

The following conclusions can be drawn based upon the data obtained from Bench Run PB-04:

HTl's newly modified P/Fe catalyst was very effective for direct liquefaction and coprocessing of Black Thunder mine subbituminous coal with Hondo resid and autofluff. During 'coal-only' liquefaction mode, under extinction recycle, over $93 \%$ maf coal conversion was obtained with about $90 \%$ residuum conversion and as high as $67 \%$ light distillate $\left(\mathrm{C}_{4}-975 \mathrm{~F}\right)$ yield. During 'coprocessing' mode of operation, distillate yields varied between 58 and $69 \%$. Residuum conversions varied between 74 and $89 \%$ maf.

- The combined processing of coal with Hondo resid and auto-fluff, carried out for the first time at $\mathrm{HTI}$, resulted in about $84 \%$ residuum conversion and over $67 \%$ light distillate yield.

- When coprocessing a mixture of $75 \%$ coal and $25 \%$ auto-fluff, total feed conversion, based upon quinoline solubility of the products, decreased; there was also a substantial drop in the resid conversion and light distillate yield. When part of the auto-fluff was replaced in the coprocessing mode by simulated MSW plastics, conversions and distillate yield increased markedly; chemical hydrogen consumption decreased with the ASR material as well as with the MSW plastics in the feed.

- Overall, it is concluded based upon the yield data from PB-04 that auto-fluff (probably containing primarily polyurethanes and high impact polystyrene) is not as effective as MSW plastics in improving coal hydroconversion process performance. Auto-fluff neither increased light distillate yields nor decreased light gas make and chemical hydrogen consumption, as was observed with MSW plastics. 


\section{Table 1. Run Plan for Bench Run PB-04}

Condition

Period Number

Work-Up Period

Dispersed Catalyst, ppm

Feed Composition, W\%

Coal
Plastics
Hondo Oil
ASR

Recycle Type

Recycle Ratio

Space Velocity, $\mathrm{kg} / \mathrm{h} / \mathrm{m}^{3}$ react

Temperatures, ${ }^{\circ} \mathrm{C}$

640

$\begin{array}{llllll} & 1 & 2 & 3 & 4 & 5 \\ & 1-5 & 13-17 & 6-12 & 18-21 & 22-25 \\ & 5 & 17 & 12 & 21 & 25 \\ \text { Iron } & 1000 & 1000 & 1000 & 1000 & 1000 \\ \text { Phosphorus } & 100 & 100 & 100 & 100 & 100 \\ \text { Molybdenum } & 50 & 50 & 50 & 50 & 50\end{array}$

5
$22-25$
25

1000
100
50

$\begin{array}{llll}0 & 50 & 75 & 50\end{array}$

$\begin{array}{llll}0 & 0 & 0 & 25\end{array}$

$70 \quad 30$

$30 \quad 20$

$\begin{array}{ll}0 & 25 \\ 25 & 0 \\ & 25\end{array}$

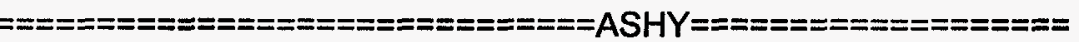

$\begin{array}{lllll}1.2 & 1.2 & 1.2 & 1.5 & 1.5\end{array}$

640

690

640

640

$\begin{array}{llllll}\text { K-1 } & 441 & 441 & 441 & 441 & 441 \\ \text { K-2 } & 449 & 449 & 449 & 449 & 449 \\ \text { In-line HTU } & 379 & 379 & 379 & 379 & 379\end{array}$


Table 2. Analysis of Black Thunder Mine Feed Coal

HTI Designation

HTI 6213

Moisture Content, W\%

10.01

Proximate Analysis, W\% Dry

Volatile Matter

43.48

Fixed Carbon

50.52

Mineral Matter

6.00

Ultimate Analysis, W\% Dry

Carbon

70.12

Hydrogen

5.11

Nitrogen

0.99

Sulfur

0.35

Ash

6.19

Oxygen (Diff.)

17.24

H/C Atomic Ratio

0.875 


\section{Table 3. Analysis of Heavy Oil, ASR, and Waste Plastics Feed}

Feed Type

Gravity, API

$524^{\circ} \mathrm{C}+$ Resid Content, V\%

Ultimate Analysis, W\% Dry
ASR

N/A

100

82.0

6.2

$(82.0$

Hondo VTB Resid

N/A

N/A

$\begin{array}{ll}\text { Carbon } & 83.84 \\ \text { Hydrogen } & 10.13 \\ \text { Nitrogen } & 0.90 \\ \text { Sulfur } & 4.39 \\ \text { Oxygen } & 0.59 \\ \text { Ash } & 0.15 \\ \text { Chlorine } & \text { N/A }\end{array}$

48.87

80.51

3.83

11.42

3.60

0.00

0.72

0.21

23.32

6.06

19.68

1.64

0.16 
Table 4. Analysis of Start-up/Make-up Oil

HTI Designation

Filtered L-814

Gravity API ${ }^{\circ}$,

0.40

ASTM D-1160 Distillation, ${ }^{\circ} \mathrm{C}$

$\begin{array}{ll}\text { IBP } & 309 \\ 5 \mathrm{~V} \% & 351 \\ 10 \mathrm{~V} \% & 374 \\ 20 \mathrm{~V} \% & 394 \\ 30 \mathrm{~V} \% & 409 \\ 40 \mathrm{~V} \% & 426 \\ 50 \mathrm{~V} \% & 437 \\ 60 \mathrm{~V} \% & 449 \\ 70 \mathrm{~V} \% & 467 \\ 80 \mathrm{~V} \% & 507 \\ 84 \mathrm{~V} \% & 524\end{array}$

Weight Percents

$\begin{array}{ll}\text { IBP }-343^{\circ} \mathrm{C} & 5.47 \\ 343-454^{\circ} \mathrm{C} & 53.99 \\ 454-524^{\circ} \mathrm{C} & 22.18 \\ 524^{\circ} \mathrm{C}^{+} & 18.36\end{array}$

Elemental Analysis, W\%

Carbon

88.96

Hydrogen

8.25

Sulfur

2.22

Nitrogen

0.19

NMR Data

W\% Aromatic Carbon

88.03

W\% Cyclic Hydrogen

44.36 
Table 5. PB-04: Process Performance Summary

DATE

Condition

Period Number

$\begin{array}{ccccc}06 / 08 / 96 & 06 / 17 / 96 & 06 / 15 / 96 & 06 / 24 / 96 & 06 / 26 / 96 \\ 1 & 2 & 3 & 4 & 5 \\ 5 & 14-15 & 12 & 21 & 23\end{array}$

Process Conditions

Space Velocity, $\mathrm{mf}$ fresh feed / reactor volume

$\mathrm{K}-1\left(\mathrm{~kg} / \mathrm{h} / \mathrm{m}^{3}\right)$

$718.4 \quad 635$

$635 \quad 602$

632

621

peratures, ${ }^{\circ} \mathrm{C}$

$\mathrm{K}-1$

$441 \quad 442$

451

441

442

441

$\mathrm{K}-2$

449

451

450

449

Feed Composition, W\%

Black Thunder Mine Coal

100

None

50

Hondo VTB Oil

N/A

70

30

75

50

ASR

N/A

30

20

None

N/A

Waste Plastics

N/A

None

None

25

25

Dispersed Catalyst Loading.ppm

Iron

1000

1000

1000

50

100

None

$25^{*}$

Molybdenum

50

50

100

1000

1000

50

50

Phosphorous

100

100

100

NET NORMALIZED YIELDS, W\% maf fresh feed

\begin{tabular}{|c|c|c|c|c|c|}
\hline $\mathrm{C}_{4}-\mathrm{C}_{3}$ in Gases & 9.89 & 6.97 & 8.56 & 6.91 & 7.83 \\
\hline $\mathrm{C}_{4}-\mathrm{C}_{7}$ in Gases & 3.47 & 3.09 & 3.32 & 6.57 & 8.15 \\
\hline IBP-177 ${ }^{\circ} \mathrm{C}\left(1 \mathrm{BP}-350^{\circ} \mathrm{F}\right)$ & 16.78 & 18.32 & 22.17 & 8.12 & 12.56 \\
\hline $177-260^{\circ} \mathrm{C}\left(350-500^{\circ} \mathrm{F}\right)$ & 10.37 & 10.88 & 11.99 & 9.35 & 9.56 \\
\hline $260-343^{\circ} \mathrm{C}\left(500-650^{\circ} \mathrm{F}\right)$ & 15.34 & 12.07 & 10.85 & 7.20 & 9.98 \\
\hline $343-454^{\circ} \mathrm{C}\left(650-850^{\circ} \mathrm{F}\right)$ & 18.47 & 18.03 & 13.57 & 18.32 & 16.79 \\
\hline $454-524^{\circ} \mathrm{C}\left(850-975^{\circ} \mathrm{F}\right)$ & 3.12 & 6.70 & 4.90 & 7.05 & 4.38 \\
\hline $524^{\circ} \mathrm{C}+\left(975^{\circ} \mathrm{F}+\right)$ & 3.73 & 15.95 & 10.47 & 18.03 & 13.99 \\
\hline Unconverted Coal & 6.82 & 3.61 & 5.97 & 9.55 & 8.78 \\
\hline Water YLD by Forced Oxygen Bal. & 12.08 & 4.37 & 9.01 & 11.32 & 8.11 \\
\hline $\mathrm{CO}_{\mathrm{x}}$ & 6.53 & 0.62 & 2.64 & 3.90 & 4.01 \\
\hline $\mathrm{NH}_{3}$ & 0.88 & 1.46 & 1.33 & 0.55 & 0.47 \\
\hline $\mathrm{H}_{2} \mathrm{~S}$ & -0.34 & 2.70 & 0.95 & -0.88 & -0.63 \\
\hline \multicolumn{6}{|c|}{ ROCESS PERFORMANCE, W\% maf fresh feed } \\
\hline Material Recovery Balance & 100.80 & 100.55 & 102.74 & 104.35 & 104.06 \\
\hline Ash Recovery & 100.21 & 99.36 & 99.43 & 99.98 & 99.90 \\
\hline Hydrogen Consumption & 7.21 & 4.76 & 5.71 & 5.99 & 3.97 \\
\hline Total Feed Conversion ( $\mathrm{SO}_{3}$ Free) & 93.21 & 96.41 & 94.07 & 90.49 & 91.25 \\
\hline $524^{\circ} \mathrm{C}+$ Conversion & 89.45 & 80.45 & 83.57 & 72.42 & 77.23 \\
\hline $\mathrm{C}_{4}-524^{\circ} \mathrm{C}$ Distillates & 67.53 & 69.09 & 66.80 & 56.61 & 61.41 \\
\hline $524^{\circ} \mathrm{C}+$ Resid Yield, maf ff & 3.73 & 15.95 & 10.47 & 18.03 & 13.99 \\
\hline
\end{tabular}

* $60 \%$ HDPE $+40 \%$ PS 
Table 6. First Stage Separator Overhead (SOH) Properties

(Composite Sample)

Condition

Period

Gravity, ${ }^{\circ} \mathrm{API}$

IBP, ${ }^{\circ} \mathrm{C}$

FBP, ${ }^{\circ} \mathrm{C}$

Elemental Analysis

Carbon, W\%

Hydrogen, W\%

Sulfur (Antek), ppm

Nitrogen (Antek), ppm

H/C Ratio

ASTM D-86 Distillation, Composition, W\%

N/A

N/A

N/A

N/A

N/A

N/A

N/A

$--$
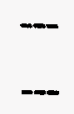

$--$

$-$

*Sample was too small.

**Sub-Period "B" only.
Loss

$177-2600 \mathrm{C}$

260-3430C

$343 \circ \mathrm{C}+$

Loss
3

$12^{* *}$

2

15

4

21

23

37.5

54

383

31.6

58

384

23.8

66.67

387

28.2

70

397
43.9

21.9

21.0

11.9

1.3
38.3

25.3

23.4

12.4

0.6
84.83

10.37

1850.1

2371.2

1.47

1.49

85.41

10.59
1813.0

2192.0

27.3

42.9

23.8

19.1

30.0

23.9

18.0

13.5

0.9

0.6 


\section{Table 7. Second Stage Separator Overhead (SOH) Properties}

(Composite Sample)

$\begin{array}{lccccc}\text { Condition } & 1 & 3 & 2 & 4 & 5 \\ \text { Period } & 6 & 12 & 15 & 21 & 23 \\ & & & & & \\ \text { Gravity, }{ }^{\circ} \mathrm{API} & 41.3 & 45.1 & 45.9 & 28.6 & 31.2 \\ \text { IBP, }{ }^{\circ} \mathrm{C} & 52 & 42 & 42 & 56 & 62 \\ \text { FBP, }{ }^{\circ} \mathrm{C} & 365 & 384 & 373 & 378 & 386\end{array}$

Elemental Analysis

Carbon, W\%

Hydrogen, W\%

Sulfur (Antek), ppm

Nitrogen (Antek), ppm

H/C Ratio
86.40

13.33

1130.0

1032.0

1.85
86.38

13.60

1109.6

933.7

1.89

1.91

1.52

1.54

85.55

11.01

2677.8
1781.1

2534.0

41.1

IBP $-177^{\circ} \mathrm{C}$

42.0

48.8

44.9

36.4

28.2

21.8

$260-343^{\circ} \mathrm{C}$

24.4

23.3

27.2

24.5

24.8

$343^{\circ} \mathrm{C}+$

4.9

6.0

6.9

9.5

11.5

1.7

1.3

0.9

1.0

0.8 
Table 8. Pressure Filter Liquid (PFL) Properties

(Composite Sample)

Condition

Period

Gravity, ${ }^{\circ} \mathrm{API}$

IBP, ${ }^{\circ} \mathrm{C}$
1

6

$-7.2$

246
3

12

$-5.0$

228
2

$15^{*}$

3.0

277
5

23

4.7

289

Elemental Analysis

Carbon, W\%

Hydrogen, W\%

Sulfur (Antek), ppm

Nitrogen (Antek), ppm

H/C Ratio
87.18

7.16

0.752

0.98

0.99

1.04

7.66

1.13

1.14

ASTM D-1160 Distillation, Composition, W\%

IBP- $343^{\circ} \mathrm{C}$
$343-454^{\circ} \mathrm{C}$
$454-524^{\circ} \mathrm{C}$
$524^{\circ} \mathrm{C}+$
Loss

Cyclohexane Insolubles

Toluene Insolubles

*Sub-period "A" only.
14.21

40.26

10.88

34.30

0.35

28.41

12.16

29.38

11.64

35.54

0.62
9.03

36.41

15.97

38.02

0.57

12.74

2.82

88.63

88.32

7.21

9.84

1.35

1.11

0.87

0.33

0.98

1.34

7.42

5.58

36.04

38.02

15.72

13.28

40.20

42.45

0.62

0.67

37.15

34.00

13.96

24.81 
Table 9. Second Stage Pressure Filter Solid (PFS) Properties

(Composite Sample)

Condition

Period

H/C Ratio

Hydrogen

Sulfur

Nitrogen

Composition, W\%

Quinoline Insolubles

50.76

Ash (in Quinoline Filt.)

27.15

4.59

27.32

Sulfur in Ash

4.59
ASTM Ash

Sulfur in Ash
3

12

2

14-15

21

$23^{*}$

51.24

3.76

2.76

0.67

0.88

0.91

0.84

0.86

60.04

4.31

2.50

0.88

0.70

0.54
62.31

24.66

5.44

3.95

42.19

4.70

36.70

4.90

29.44

26.78

1.56

5.03

"Sub-Period "A" Only. 
Table 10. Composite Feed Analysis

Period 5 Period 12 Per 14/15 Period 21 Period 23

Feed Composition, W\%

Coal

Oil

Auto Shredder Residue

Plastics

100

0.0

50.0

0.0

75.0

50.0

0.0

30.0

70.0

0.0

0.0

0.0

20.0

30.0

25.0

25.0

0.0

25.0

Total

100.0

0.0

0.0

25.0

100.0

100.0

100.0

100.0

Ultimate Analysis, W\%

Carbon

70.12

69.98
6.36

73.34

64.80

69.75

Hydrogen

5.11

6.36

8.24

4.79

6.04

Nitrogen

0.99

1.49

1.71

1.64

1.40

0.53

1.73

3.29

0.58

0.45

Oxygen

Ash

17.50

13.59

7.41

18.96

14.58

5.75

6.86

6.01

9.23

7.80

Total

100.00

100.00

100.00

100.00

100.00

Heating Value, BTU/lb

12,145

13,265

15,488

11,051

12,899 
Table 11. Material Balance Based on a Feed Rate of 12,000 T/D

\begin{tabular}{|c|c|c|c|c|}
\hline riod 5 & Period 12 & Per $14 / 15$ & Period 21 & Period 23 \\
\hline & & & & \\
\hline
\end{tabular}

Feed, T/D

Coal

12,000

6,000

Oil

Auto Shredder Residue

Plastics

Total

$\begin{array}{rr}0 & 3,600 \\ 0 & 2,400 \\ 0 & 0 \\ 12,000 & 12,000\end{array}$

0
8,400
3,600
0

9,000

6,000

12,000

12,000

12,000

3,000

3,000

3,000

12,000

Liquid Products, B/D

\section{Gasoline}

Diesel Fuel

Total

Barrels of Products/Ton feed

$\begin{array}{lllll}13,944 & 13,196 & 13,277 & 10,141 & 12,205 \\ 33,863 & 32,048 & 32,244 & 24,629 & 29,641 \\ 47,807 & 45,244 & 45,521 & 34,770 & 41,846\end{array}$

3.98

3.77

3.79

2.90

3.49

By-products

Propane, B/D

Butane, B/D

Sulfur, LT/D

Ammonia, T/D

Waste to Disposal, T/D

$\begin{array}{rrrrr}4,106 & 3,832 & 3,280 & 2,455 & 2,824 \\ 2,025 & 2,108 & 2,312 & 1,816 & 1,911 \\ 55 & 181 & 328 & 60 & 46 \\ 100 & 149 & 165 & 60 & 52 \\ 1,009 & 3,651 & 5,182 & 4,886 & 4,497\end{array}$




\title{
Table 12. Hydrogen Balance, Utilities Production \& Thermal Efficiency
}

\author{
Period 5 Period $12 \quad$ Per Period 21 Period 23 \\ $14 / 15$ \\ Coal only Coal/Oil/ASR Oil/ASR Coal/ASR Coal/ASR/Pls
}

\section{Hydrogen Balance}

Hydrogen Consumption. MMSCFD

Liquefaction

353.1

Product Upgrading

Solution \& Purge Loss

Total

$-28.1$

15.7

340.7

Hydrogen Production, MMSCFD

via Partial Oxidation

via Steam Reforming

Total

$\begin{array}{rrrrr}106.3 & 168.3 & 182.7 & 266.6 & 209.3 \\ 234.4 & 97.7 & 0 & 28 & 35.5 \\ 340.7 & 266 & 182.7 & 294.6 & 244.8\end{array}$

Utilities Produced or Purchased

Power, MW

236

207

161

Cooling water, 1000 GPM

Purchased Natural Gas, MMMBTU/D

100.9

Raw water, $1000 \mathrm{gal} / \mathrm{d}$

6277

284.6
-31.8
13.2
266

168.3
97.7
266

222.5

340.6

235.1

$-50.4$

$-57.9$

$-2$

10.6

11.9

11.7

182.7

294.6

244.8

Thermal Efficiency

inputs. MMMBTU/D

Feed

291.5

318.4

371.7

265.2

309.6

Natural Gas

100.9

61

45.3

38.7

67.9

Total

392.4

379.4

417

303.9

377.5

Outputs. MMMBTU/D

Gasoline

Diesel

78

73.8

74.3

56.6

68.2

196.6

186.1

187.2

142.8

172

15.8

14.7

12.6

9.4

10.9

Butane

Sulfur \& Ammonia

9.2

10.1

7.9

8.3

2.4

4.5

6.1

1.7

1.4

Total

301.6

288.3

290.3

218.4

260.8

Thermal Efficiency, \%

76.9

69.6

71.9

69.1 
Table 13. Liquefaction Plant Investment Details

\begin{tabular}{|c|c|c|c|c|}
\hline Period 5 & Period 12 & Per 14/15 & Period 21 & Period 23 \\
\hline oal & Coal/O & Oil/ASR & Coal/ASR & Coa \\
\hline
\end{tabular}

Major Equipment Cost. \$M

Pumps

Reactors \& Hydrotreater

Fired Heaters

Exchangers

Drums

Towers

Compressors

HPU

Total

Plant Investment. \$MM

Materials \& Equipment

Labor \& Subcontracts

Indirects

Total Liquefaction Plant Investment, \$MM

$\begin{array}{rrrrr}24,287 & 24,110 & 25,709 & 22,572 & 28,797 \\ 42,945 & 45,313 & 38,879 & 44,219 & 43,481 \\ 13,233 & 13,239 & 14,562 & 13,875 & 19,663 \\ 22,175 & 20,708 & 19,619 & 19,946 & 22,924 \\ 33,140 & 29,962 & 25,911 & 29,320 & 31,436 \\ 9,060 & 8,432 & 7,997 & 8,514 & 9,544 \\ 38,001 & 34,245 & 29,984 & 37,100 & 31,431 \\ 22,105 & 19,635 & 16,706 & 18,292 & 17,736 \\ & & & & \\ 204,946 & 195,644 & 179,367 & 193,838 & 205,012\end{array}$

371.3

354.5

325.0

351.2

371.5

160.7

153.4

140.6

117.0

152.0

160.7

126.4

133.7

665.7

635.5

582.6

629.6

665.9 
Table 14. Total Plant Investment Summary

(Plant Investment in \$MM, 1994 US Gulf Coast basis)

Plant Section

Coal Preparation

Oil Storage \& Handling

Auto Shredder Residue Prep'n

Plastics Preparation

Liquefaction

Hydrogen Manufacture

Oxygen Plant

Treating

Product Upgrading

Utilities

Tankage, Waste Handling

General Offsites

Subtotal

Fee, Contingency

Total Plant Investment

\$BPD of Product

\section{Period 5}

Coal only

239.7

0.0

0.0

0.0

665.7

297.4

56.4

297.2

117.0

291.1

157.2

211.0

$2,332.7$

466.1

$2,798.8$

Coal/Oil/ASR

$\frac{\text { Per } 14 / 15}{\text { Oil/ASR }}$

Period 21

Coal/ASR

Period 23

Coal/ASR/PIs

137.7

0.0

190.5

137.7

37.8

0.0

0.0

28.5

24.6

24.6

0.0

0.0

13.3

635.5

244.7

582.6

629.6

665.9

160.6

243.5

218.0

77.9

82.5

107.3

90.8

284.7

267.6

232.4

249.9

114.2

119.2

106.9

131.6

314.0

386.8

312.8

291.4

172.4

183.3

153.3

169.4

211.0

211.0

211.0

211.0

$2,233.6$

$2,059.9$

$2,211.9$

$2,203.6$

446.2

411.3

441.7

440.1

$2,679.8$

$2,471.2$

$2,653.6$

$2,643.7$

58,544

59,230

54,287

76,319

63,177 
Table 15. Product Cost Calculation

$\begin{array}{rrrrr}\text { Period } 5 & \text { Period 12 } & \text { Per 14/15 } & \text { Period 21 } & \text { Period 23 } \\ \text { Coal only } & \text { Coal/Oil/ASR } & \text { Oil/ASR } & \text { Coal/ASR } & \text { Coal/ASR/Pls }\end{array}$

Operating Costs, \$MM/year

Coal, as received $(\$ 7.00 / T)$
Oil $(\$ 8.00 / \mathrm{B})$
Auto Shredder Residue $(\$ 0.00 /$
Plastics $(\$ 0.00 / T 0 n)$
Natural gas $(\$ 2.00 / \mathrm{MMBTU})$
River Water $(\$ 2.50 / \mathrm{Mgal})$
Catalysts \& Chemicals
Dispersed Catalyst
Supported Catalyst
Ash disposal $(\$ 5.00 / \mathrm{T})$
Labor
Maintenance
Capital-Related
Total

Byproduct credits, \$MM/year

Propane $(\$ 12.50 / \mathrm{B})$
Butane $(\$ 14.50 / \mathrm{B})$
Sulfur $(\$ 52.00 / \mathrm{T})$
Ammonia $(\$ 120.00 / \mathrm{T})$
Total
Net Product Cost, $\$ M M /$ year
Net Product Cost, $\$ / \mathrm{B}$
Crude Oil Equivalent Factor

Equivalent Crude Oil Price, $\$ / B$

$\begin{array}{rrrrr}32.46 & 16.23 & 0.00 & 24.35 & 16.23 \\ 0.00 & 52.61 & 122.76 & 0.00 & 0.00 \\ 0.00 & 0.00 & 0.00 & 0.00 & 0.00 \\ 0.00 & 0.00 & 0.00 & 0.00 & 0.00 \\ 66.32 & 40.09 & 29.77 & 25.42 & 44.59 \\ 5.15 & 7.15 & 8.97 & 6.30 & 6.12 \\ 16.59 & 9.93 & 5.30 & 5.83 & 6.05 \\ 7.53 & 7.53 & 7.53 & 7.53 & 7.53 \\ 0.00 & 0.00 & 0.00 & 0.00 & 0.00 \\ 1.66 & 6.00 & 8.51 & 8.02 & 7.39 \\ 24.43 & 24.43 & 24.43 & 24.43 & 24.43 \\ 21.89 & 21.89 & 21.89 & 21.89 & 21.89 \\ 418.18 & 400.30 & 371.38 & 391.23 & 393.47 \\ 594.21 & 586.16 & 600.54 & 515.00 & 527.70 \\ & & & & \\ & & & & \\ 16.86 & 15.74 & 13.47 & 10.08 & 11.60 \\ 9.65 & 10.04 & 11.01 & 8.65 & 9.10 \\ 0.94 & 3.09 & 5.60 & 1.03 & 0.79 \\ 3.94 & 5.89 & 6.51 & 2.38 & 2.06 \\ 31.39 & 34.76 & 36.59 & 22.14 & 23.55 \\ 562.82 & 551.40 & 563.95 & 492.86 & 504.15 \\ 35.84 & 37.10 & 37.71 & 43.15 & 36.68 \\ 0.830 & 0.836 & 0.839 & 0.863 & 0.834 \\ & & & & \\ 29.76 & 31.02 & 31.63 & 37.25 & 30.59\end{array}$


Table 16. Breakdown of Equivalent Crude Oil Price

$\frac{\text { Period } 5}{\text { Coal only }} \frac{\text { Period 12 }}{\text { Coal//II/ASR }} \quad \frac{\text { Per 14/15 }}{\text { Oil/ASR }} \quad \frac{\text { Period } 21}{\text { Coal/ASR }} \quad \frac{\text { Period } 23}{\text { Coal/ASR/Pls }}$

Contribution to Price. \$/B

Coal

Oil

Auto Shredder Residue

Plastics

Natural Gas

Water

Dispersed Catalyst

Supported Catalyst

Other Catalysts \& Chemicals

Waste disposal

Labor

Maintenance

Capital Related Costs

By-product Credit

Equivalent Crude Oil Price, \$/B
1.72

0.00

0.00

0.00

3.51

0.27

0.40

0.00

0.88

0.09

1.29

1.16

22.11

$-1.66$

29.76

0.00

6.89

0.00

0.00

1.67

0.50

0.42

0.00

0.30

0.48

1.37

1.23

20.83

$-2.05$

$-1.96$

31.02

31.63

1.84

0.98

0.00

0.00

0.00

0.00

0.00

0.00

1.92

2.71

0.48

0.37

0.57

0.46

0.00

0.00

0.44

0.37

0.61

0.45

1.85

1.48

1.65

1.33

29.57

$-1.67$

23.87

$-1.43$

37.25

30.59 
Table 17. Economic Comparison of Cases at Maximum Reactor Throughput

\begin{tabular}{|c|c|c|c|c|c|}
\hline & $\frac{\text { Period } 5}{\text { Coal only }}$ & $\frac{\text { Period } 12}{\text { Coal/Oil/ASR }}$ & $\frac{\text { Per } 14 / 15}{\text { Oil/ASR }}$ & $\frac{\text { Period } 21}{\text { Coal/ASR }}$ & $\frac{\text { Period } 23}{\text { Coal/ASR/Pls }}$ \\
\hline Total Feed to Liquefaction, T/D & 12,000 & 12,940 & 18,100 & 12,940 & 14,000 \\
\hline Number of Liquefaction trains & 4 & 4 & 4 & 4 & 4 \\
\hline Total feed, T/D per train & 3,000 & 3,235 & 4,525 & 3,235 & 3,500 \\
\hline Liquid Product, B/D & 47,807 & 48,773 & 68,562 & 37,479 & 48,788 \\
\hline Liquefaction Plant Cost, \$MM & 665.7 & 672.4 & 790.8 & 667.4 & 746.9 \\
\hline Total Plant Investment, \$MM & 2,799 & 2,837 & 3,346 & 2,805 & 2,957 \\
\hline Net Annual operating Cost, \$MM & 562.8 & 583.6 & 773.3 & 519.5 & 561.9 \\
\hline Net Product Cost, \$/B & 35.84 & 36.42 & 34.33 & 42.20 & 35.06 \\
\hline Equivalent Crude Oil Price, $\$ / B$ & 27.96 & 30.34 & 28.28 & 36.25 & 28.99 \\
\hline
\end{tabular}


Figure 1. Simplified Schematic of HTI's Bench Unit Configured for Run PB-04

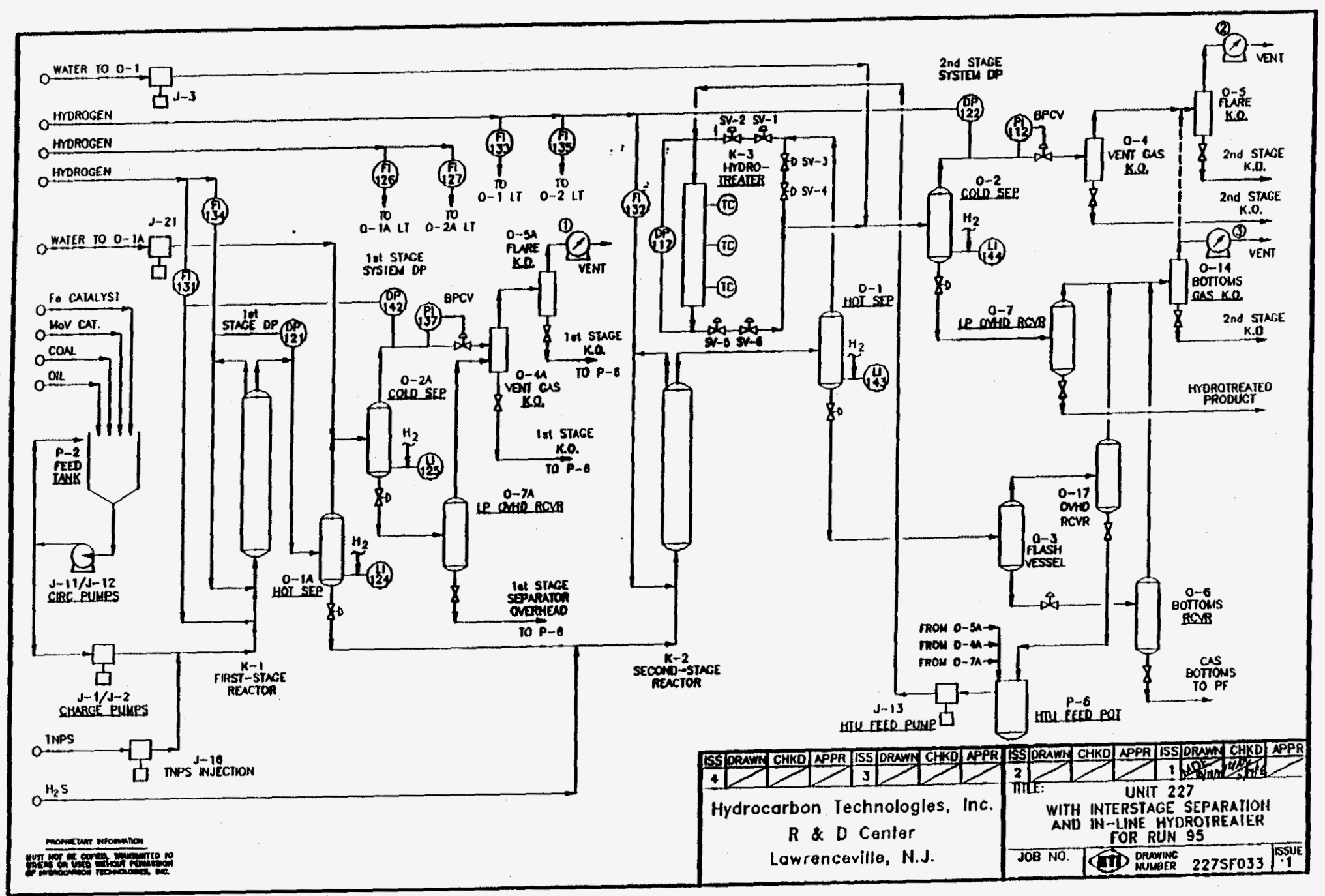


Figure 2. PB-04: Daily Operating Conditions

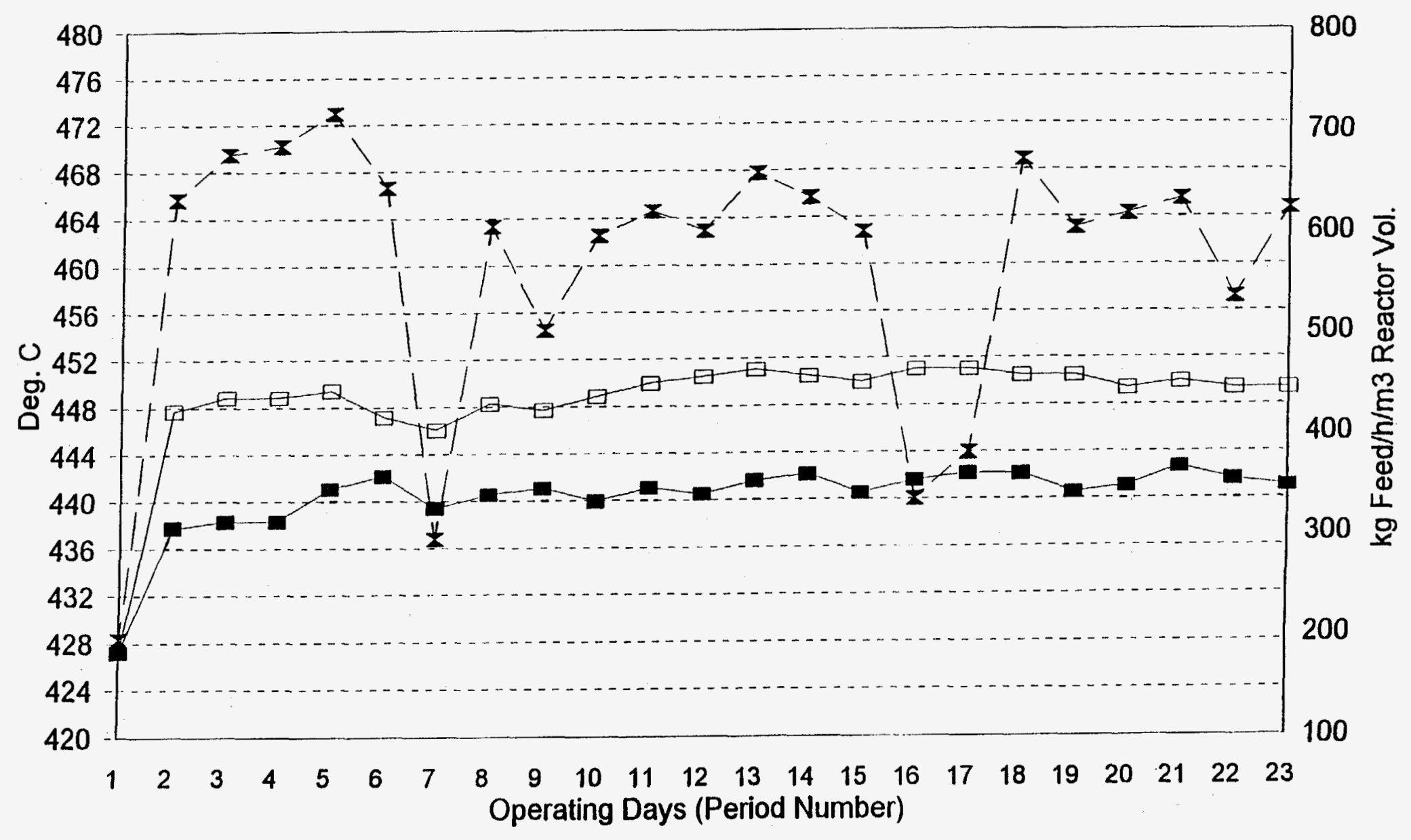

- K-1 Temp - - K-2 Temp - - - Space Velocity 


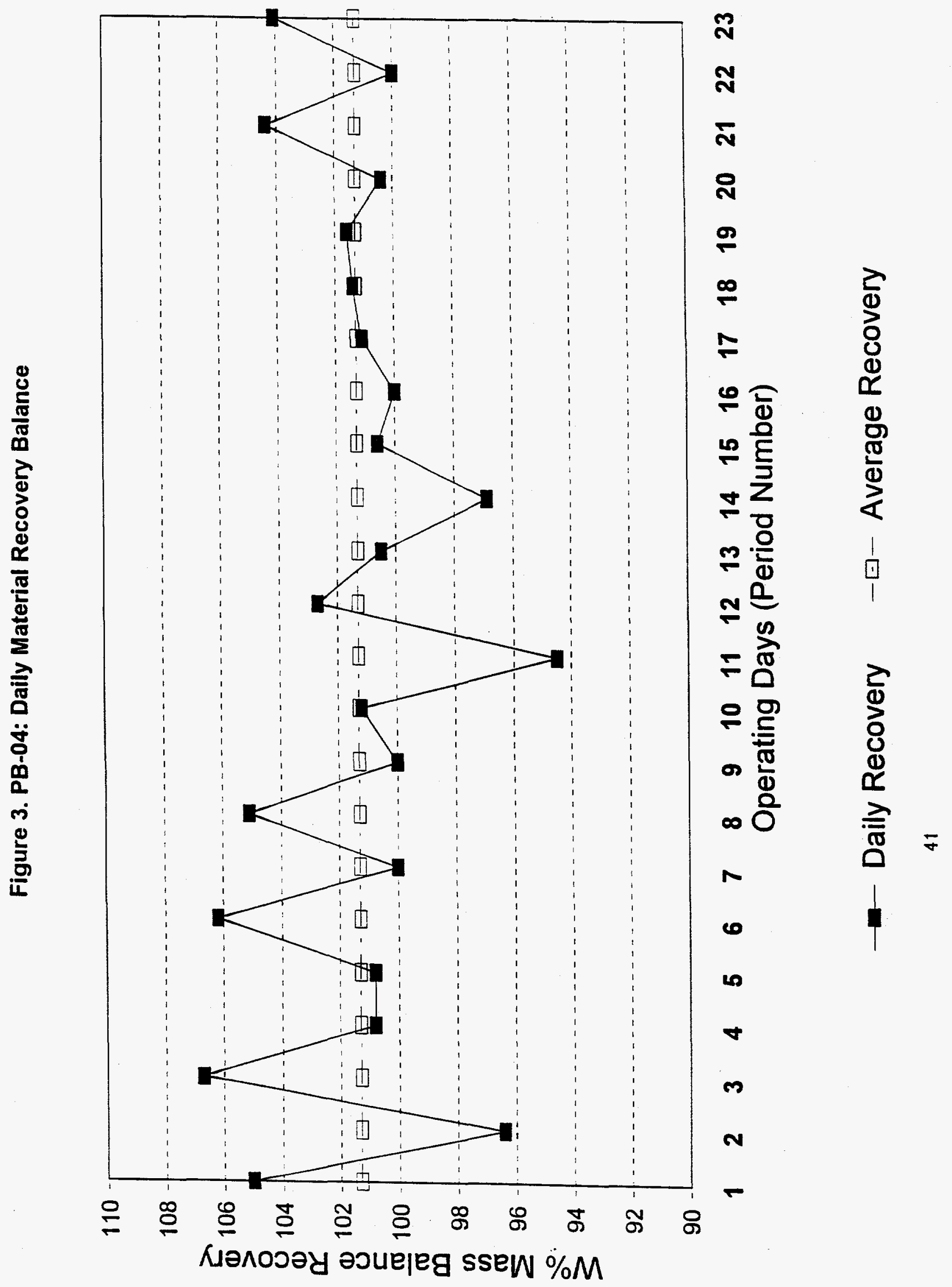




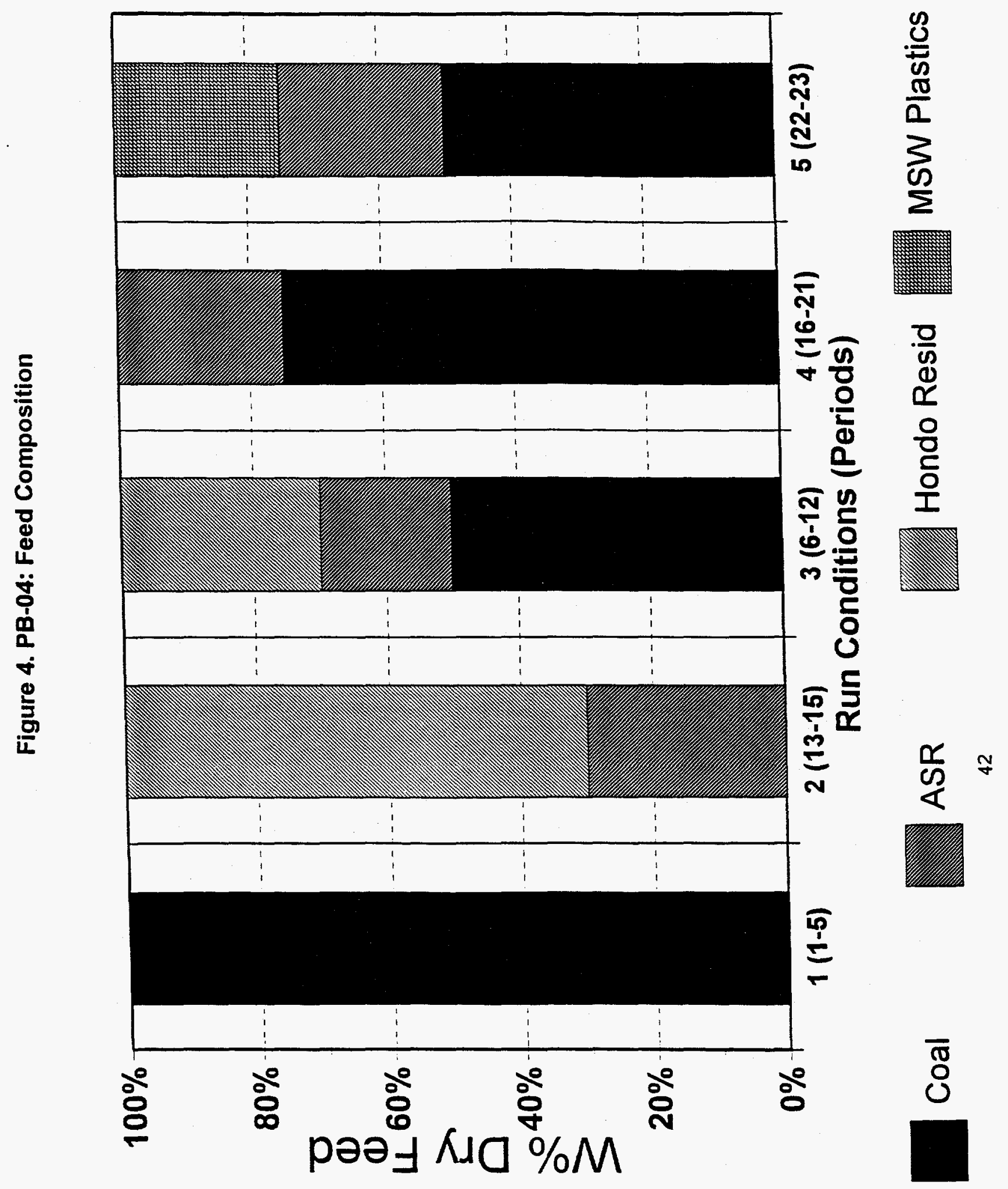




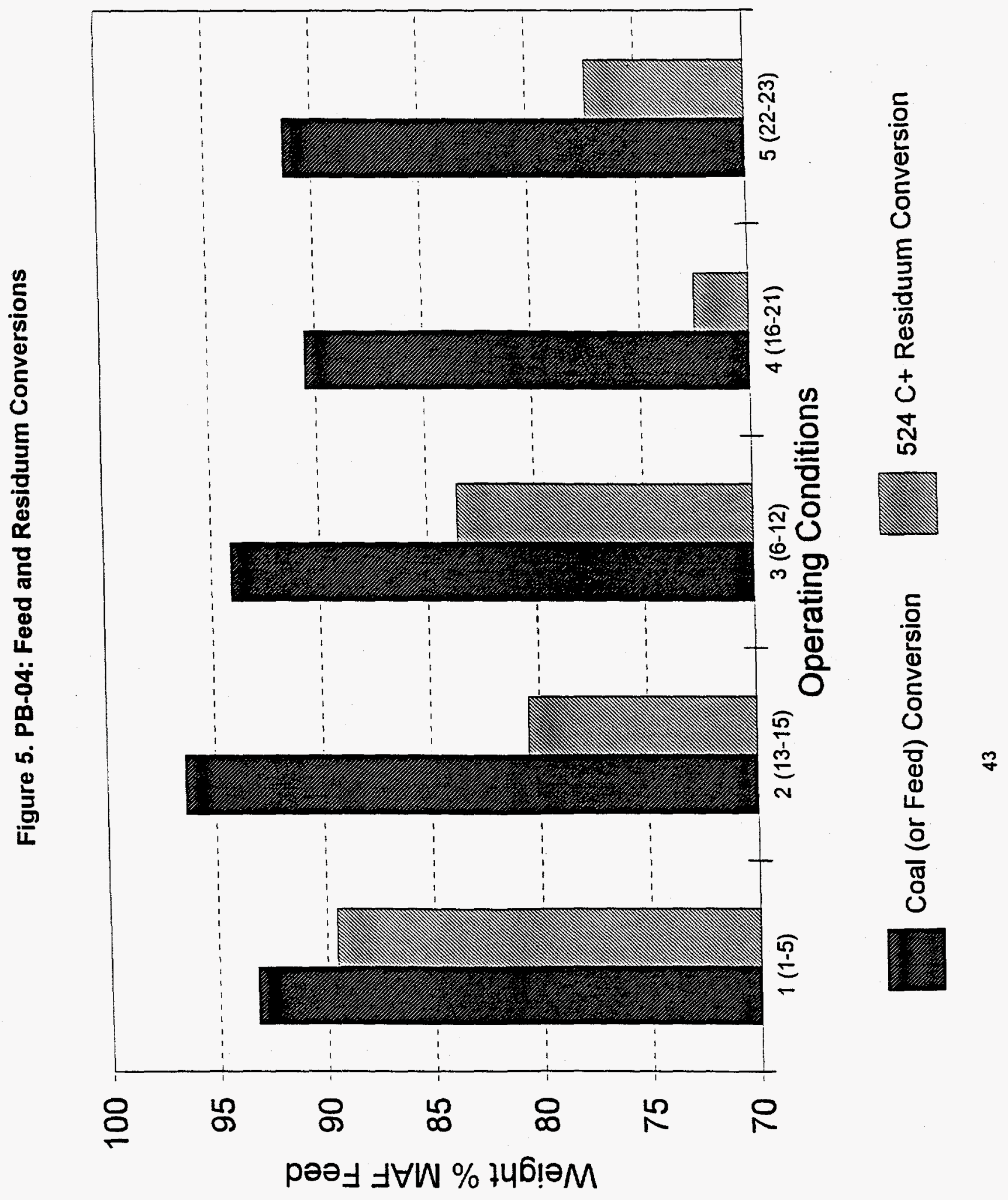




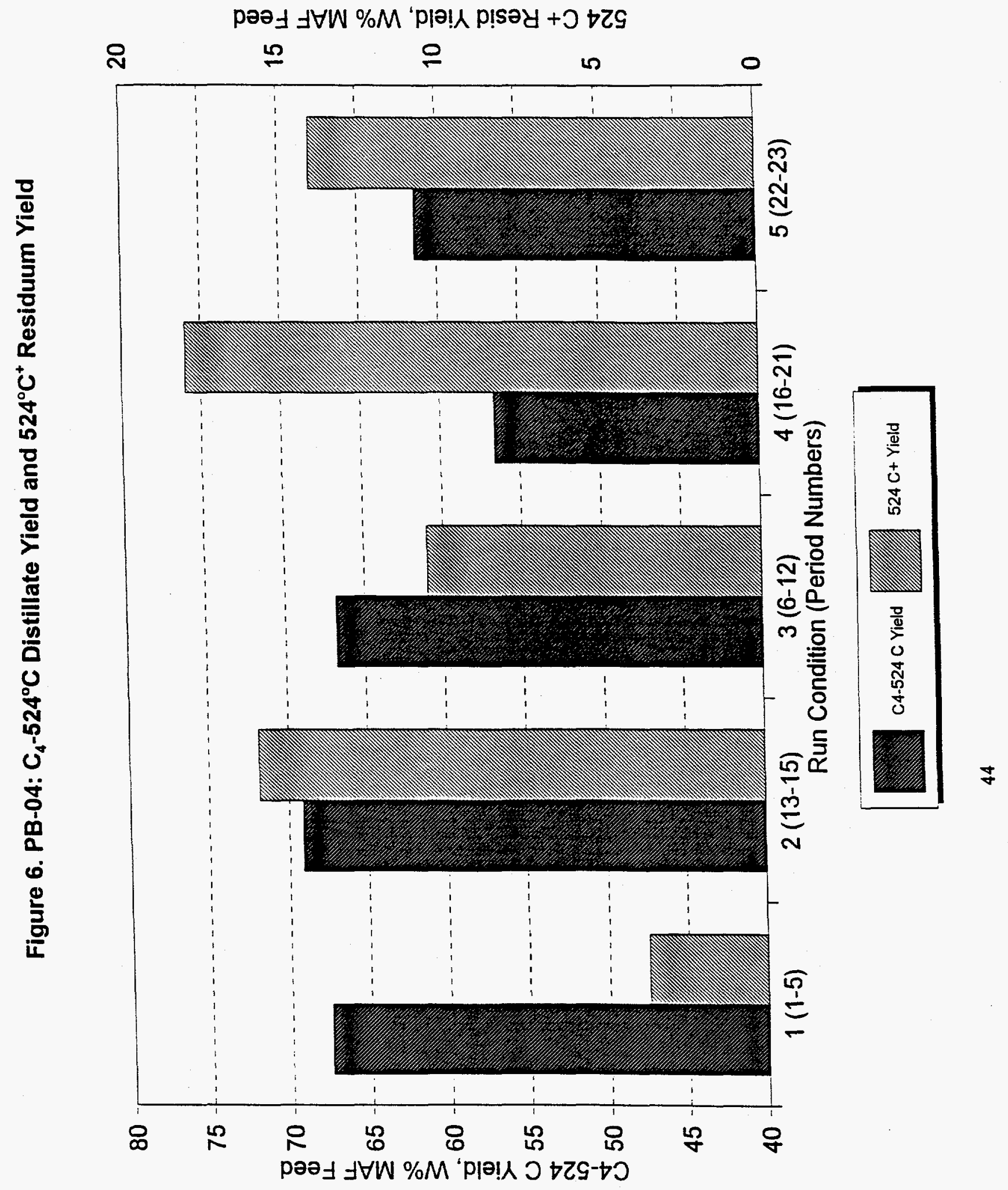




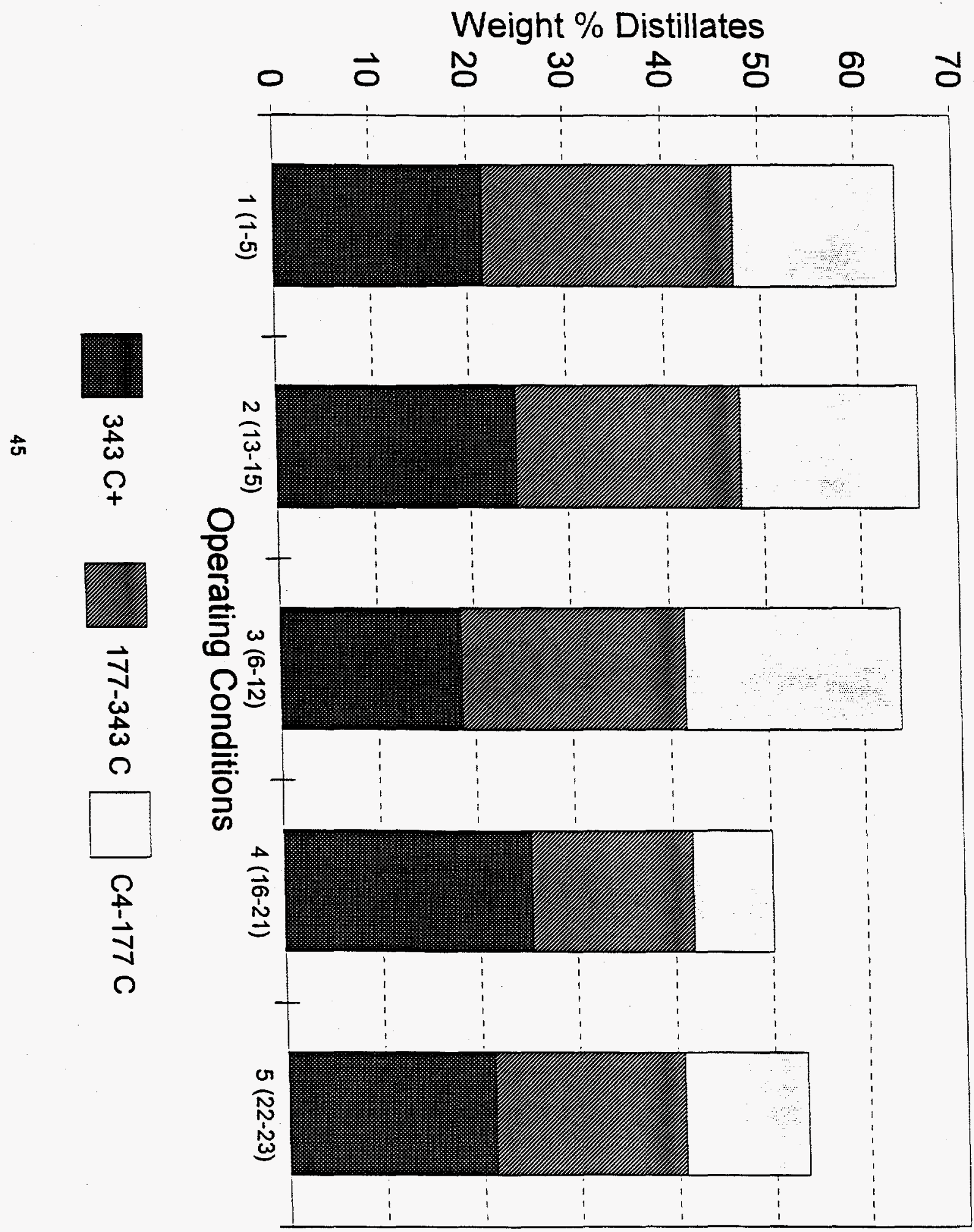

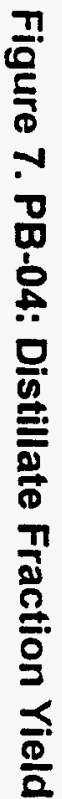




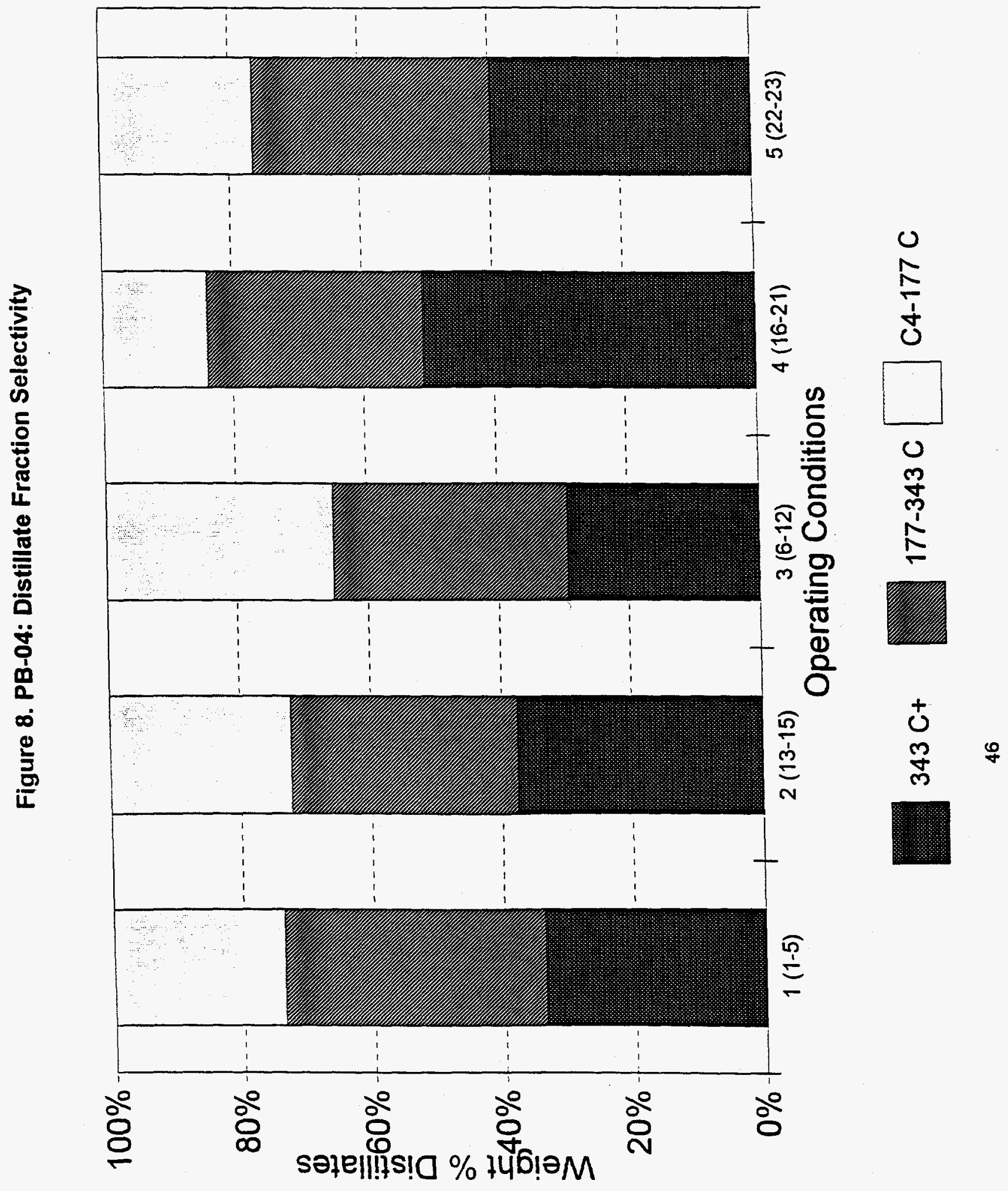




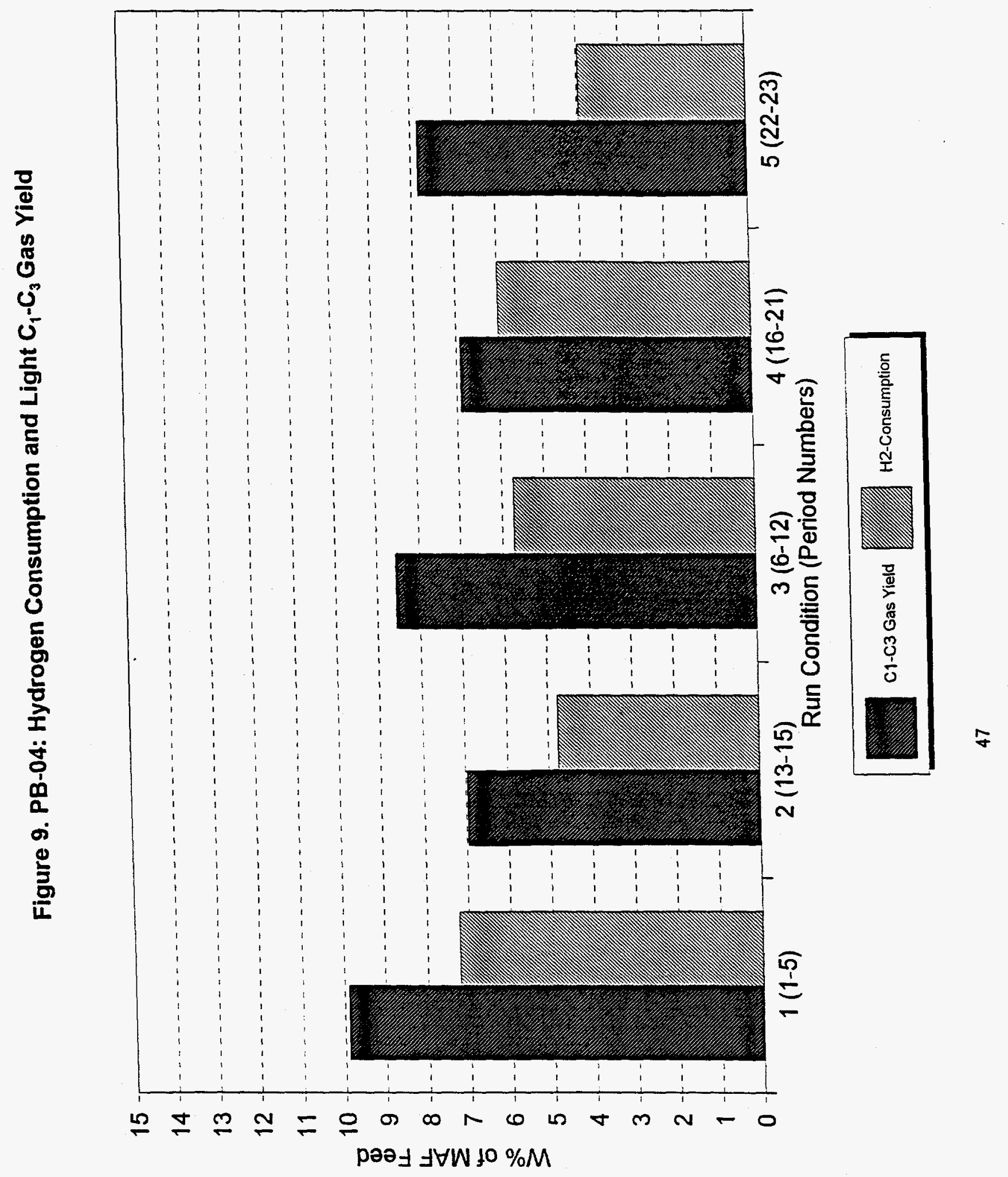


Figure 10. PB-04: Hydrogen Efficiency and $C_{1}-C_{3}$ Gas Selectivity
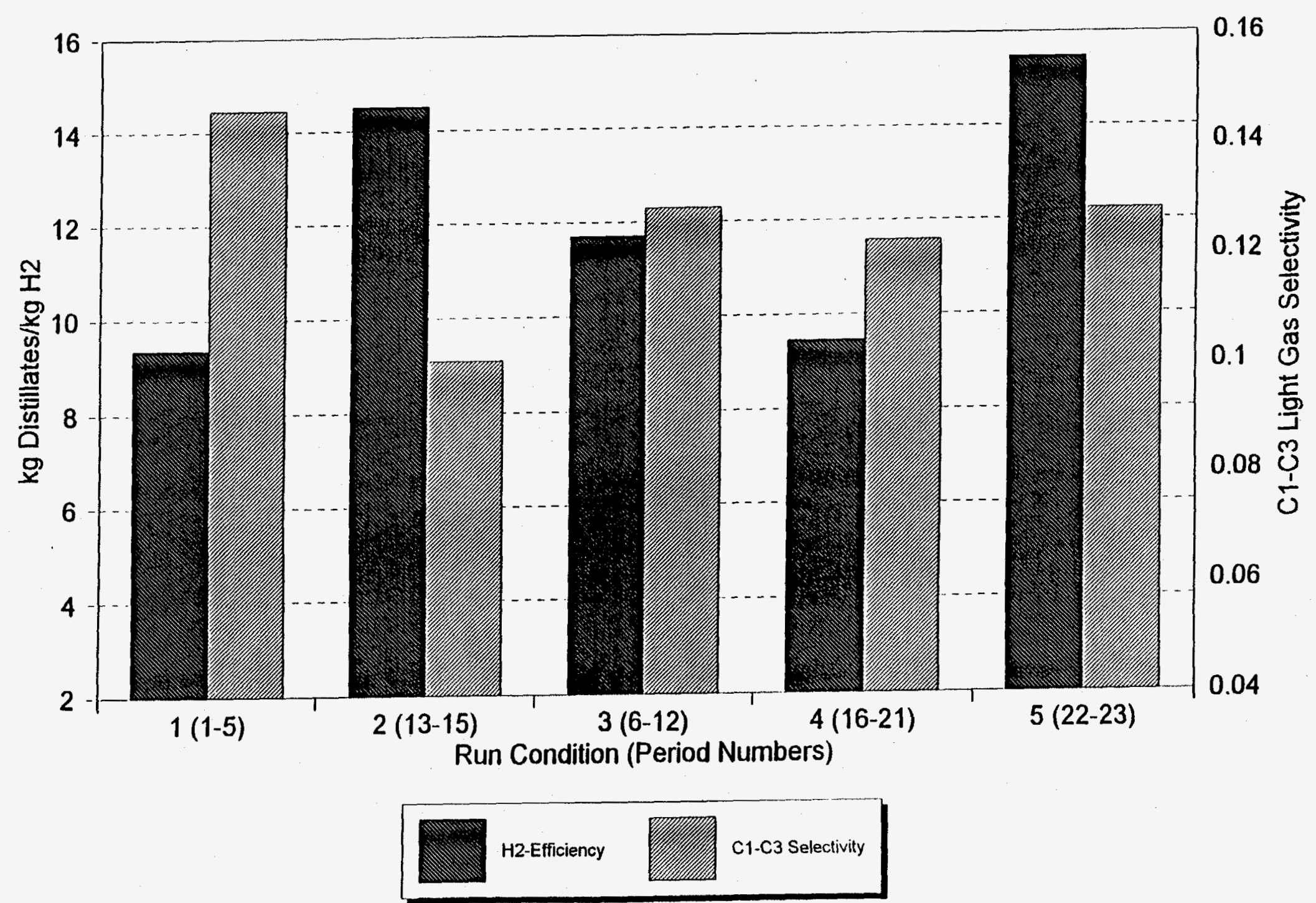


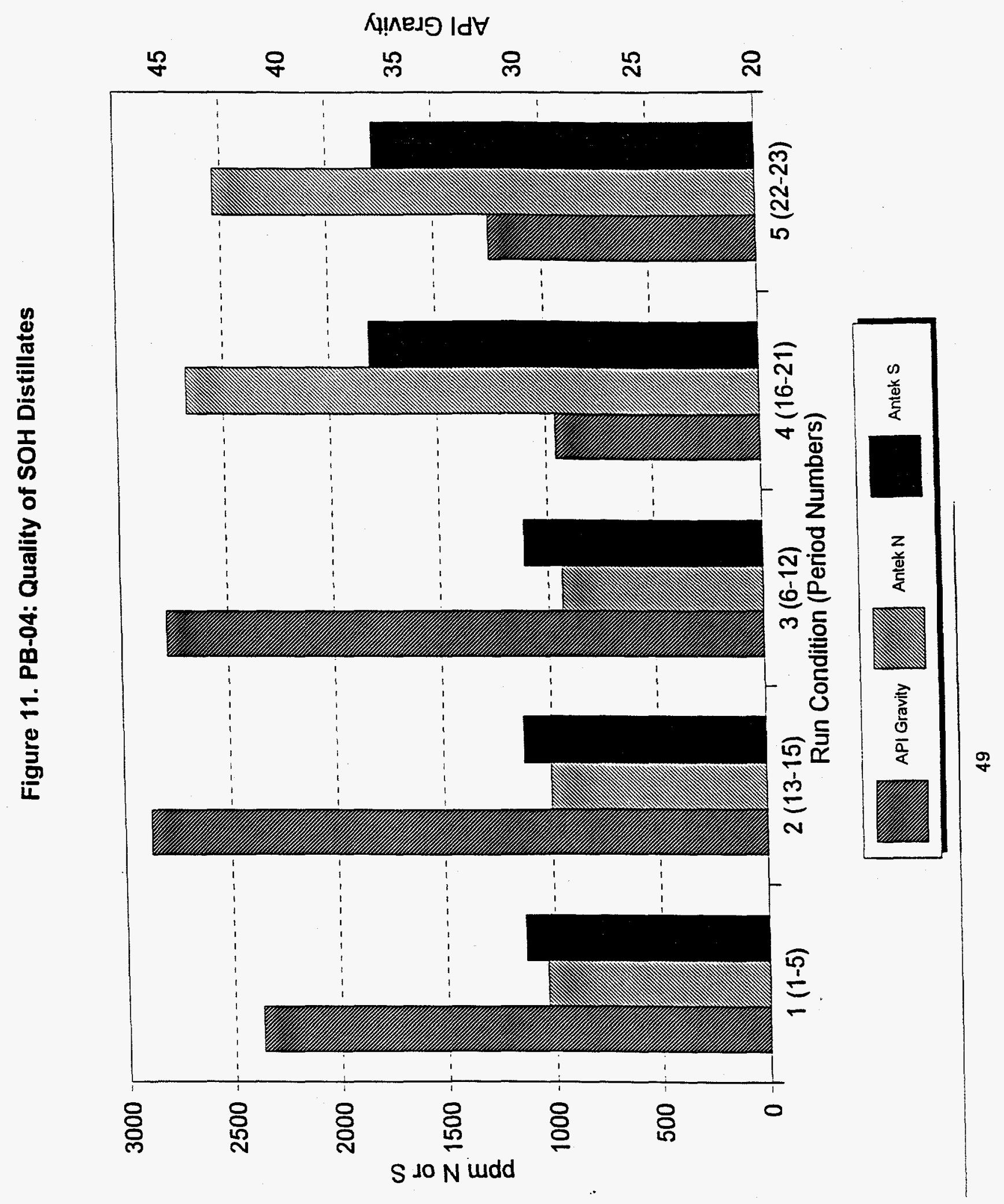


Figure 12. PB-04: Product H/C Ratios

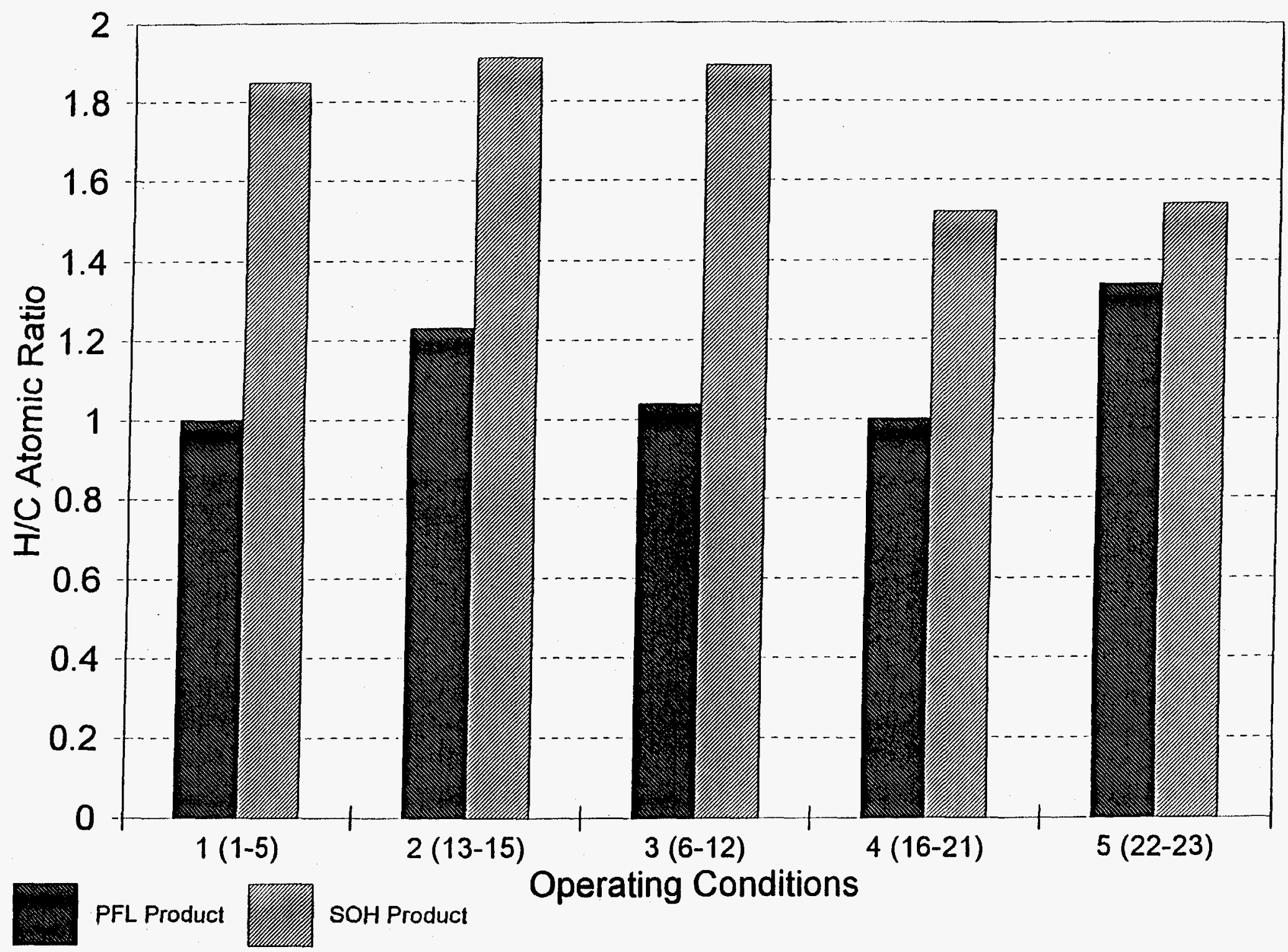




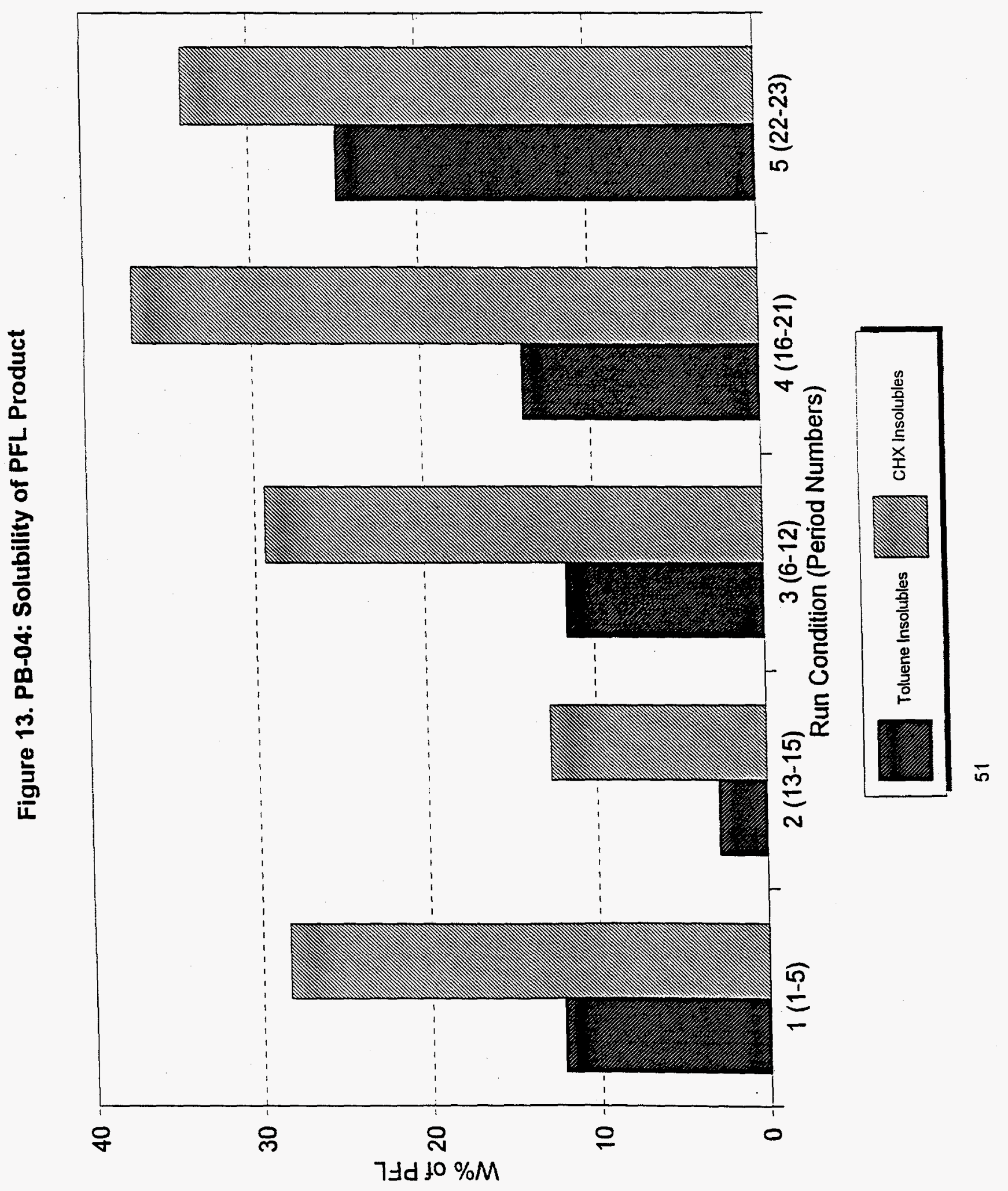


Figure 14. PB-04: Effect of Dispersed Catalyst and Extinction Recycle on Process Performance (I)

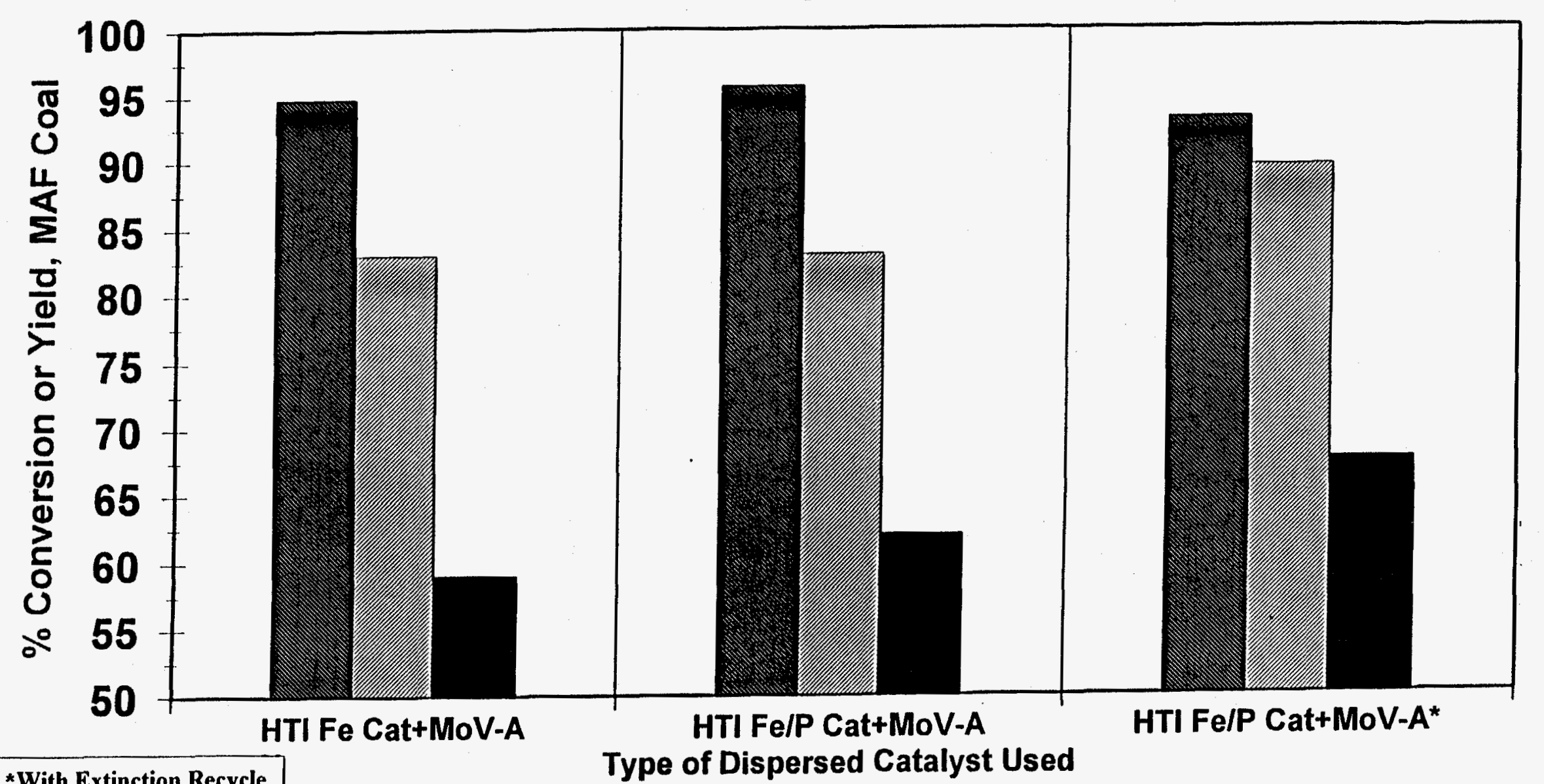

*With Extinction Recycle Mode of Operation! 
Figure 15. PB-04: Effect of Dispersed Catalyst and Extinction Recycle on Process Performance (II)

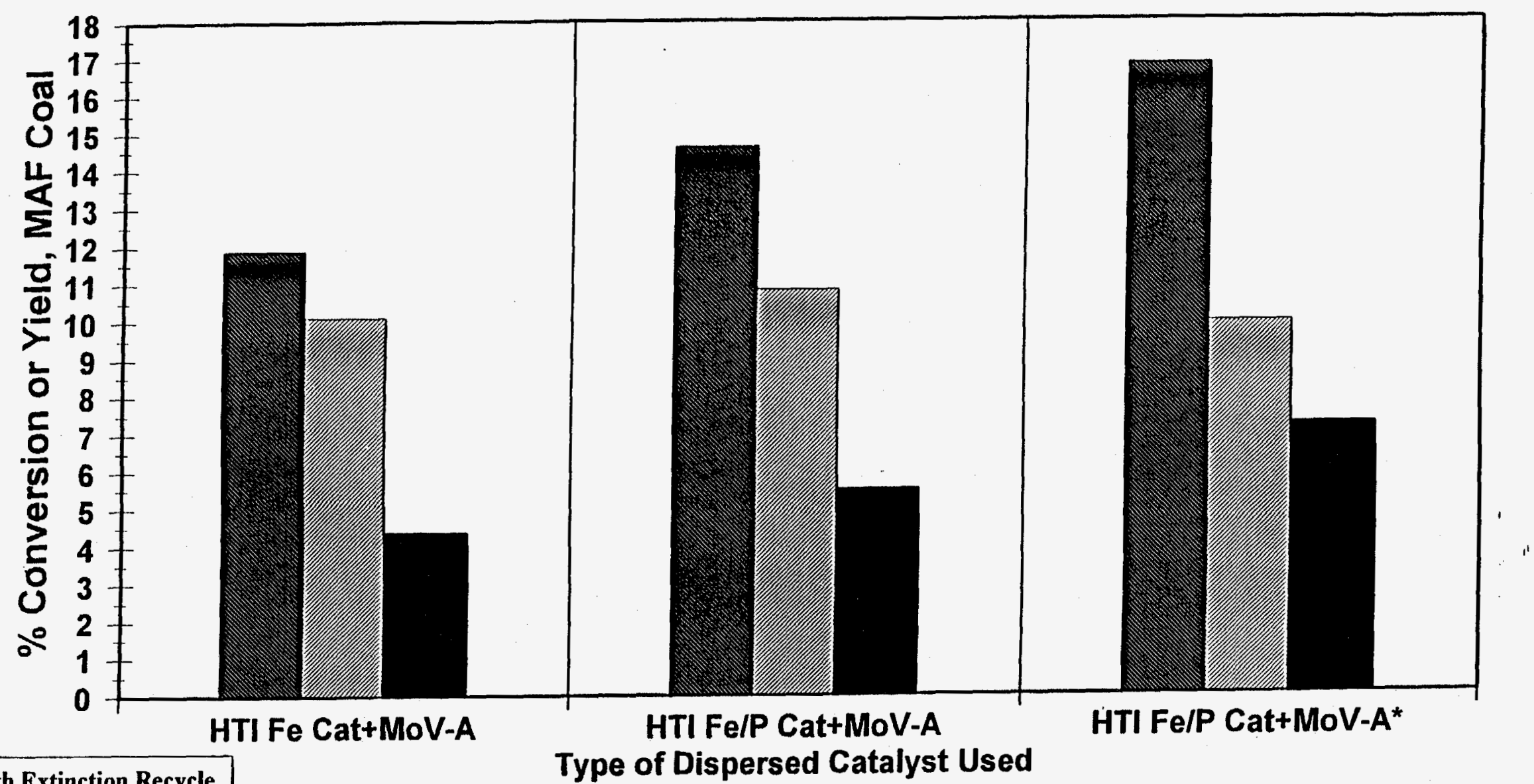

*With Extinction Recycle Mode of Operation!

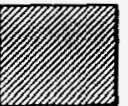




\section{pəəコ $\exists \forall W \% M$}

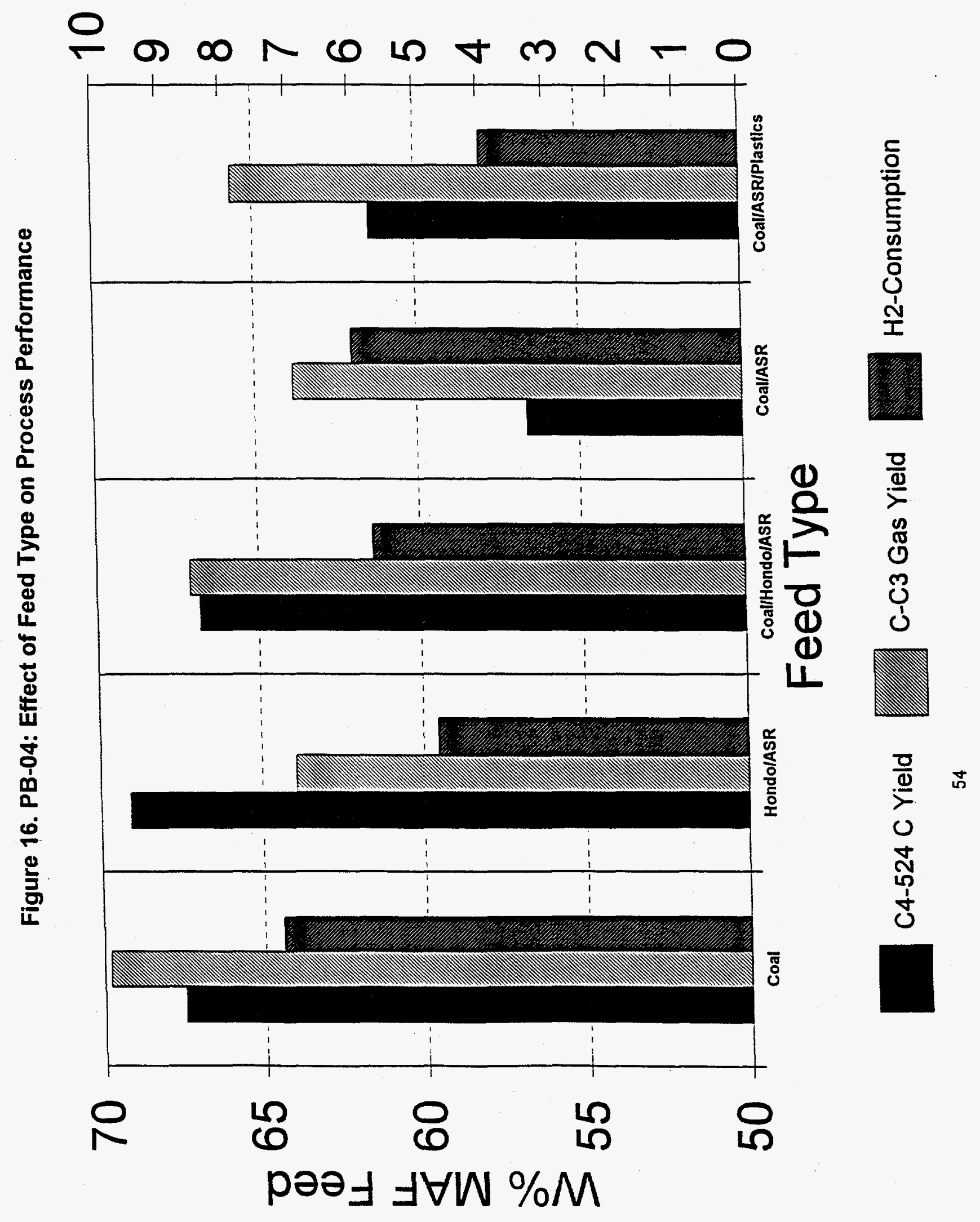


Figure 17. PB-04: Economic Effect of ASR Cost

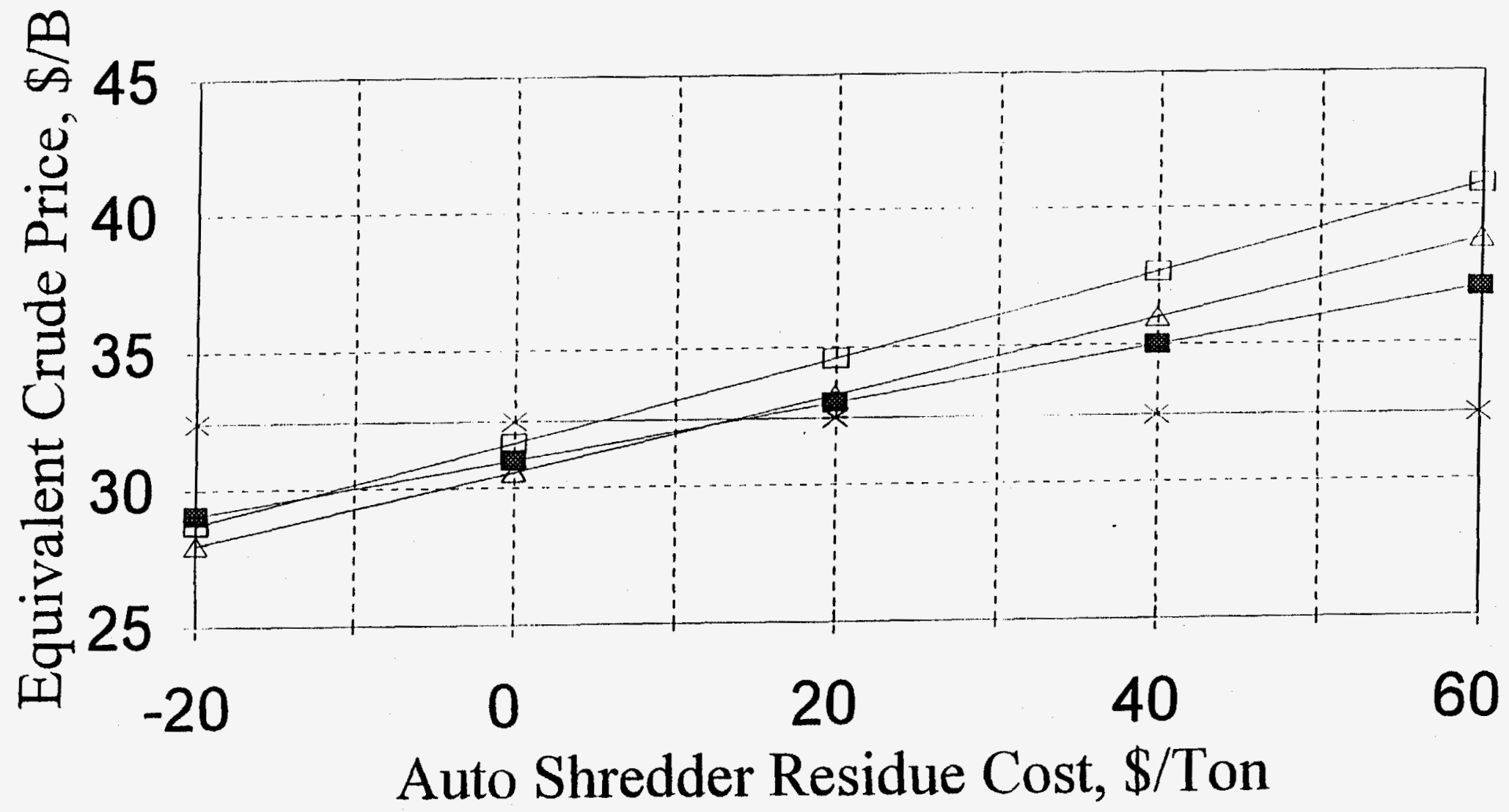

- Period $12 \nleftarrow$ Per 14/15 $\triangle$ Period $23 *$ Base 


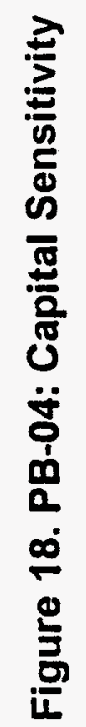

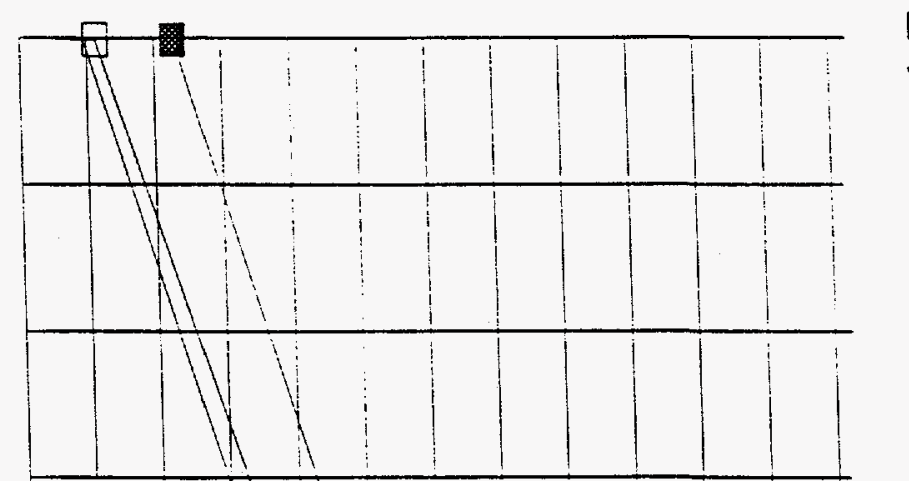

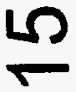

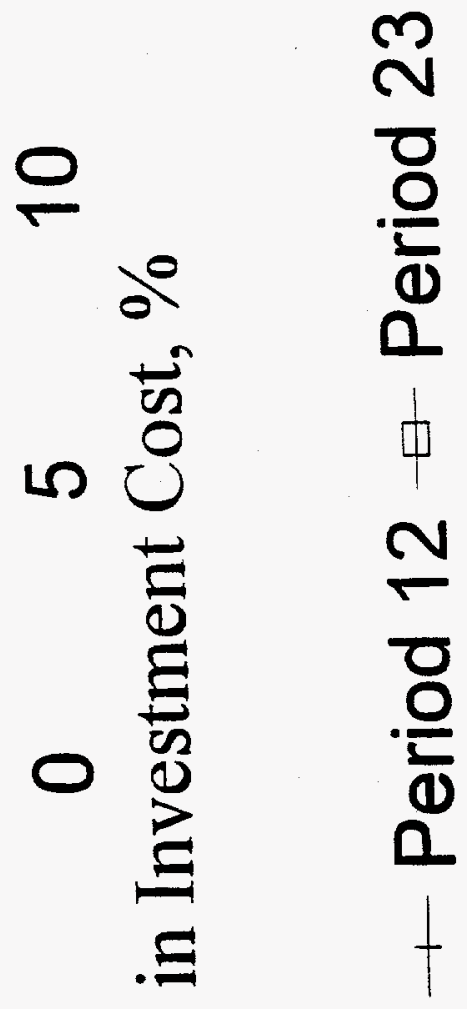

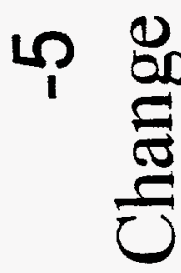

L

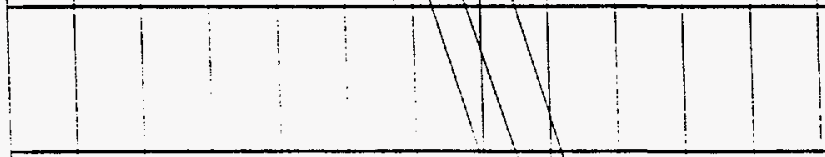

$\frac{0}{1}$

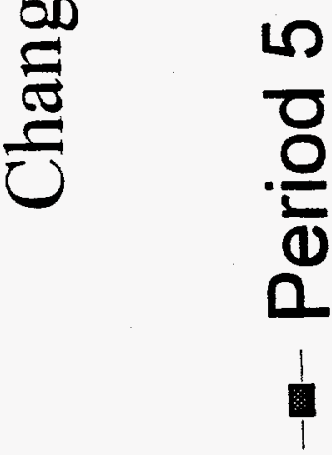

๓̊

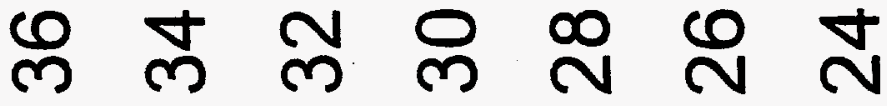

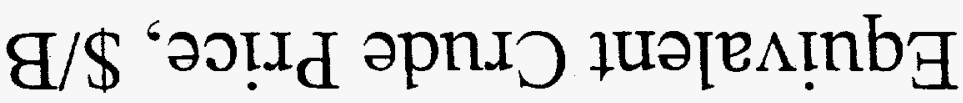




\section{ABBREVIATIONS}

ASR

PFL

PFS

$\mathrm{SOH}$

$\mathrm{H} / \mathrm{C}$

VTB

MSW

VSB

$\mathrm{VSOH}$

HTU

EO

EC

TNPS

$S / U$

$S / D$
Automobile Shredder Residue

Pressure Filter Liquid

Pressure Filter Solid

Separator Overhead Product

Hydrogen-to-Carbon Atomic Ratio

Vacuum Tower Bottoms

Municipal Solid Waste

Vacuum Still Bottoms

Vacuum Still Overhead Product

Hydrotreating Unit

Toluene-Extracted Oil

Toluene-Extracted Cake

Tertiary Nonyl Polysulfide

Unit Start-up

Unit Shut-down 
227-95 Condition 1 Results

Co-processing of Auto-Fluff and/or Waste Plastics with Coal/Petroleum Resid

\begin{tabular}{|c|c|c|c|c|c|c|}
\hline $\begin{array}{l}\text { DATE } \\
\text { PERIOD }\end{array}$ & $\begin{array}{c}\text { 04-Jun-96 } \\
1\end{array}$ & $\begin{array}{l}\text { 05-Jun-96 } \\
2\end{array}$ & $\begin{array}{l}06-J u n-96 \\
3\end{array}$ & $\begin{array}{c}\text { 07-Jun-96 } \\
4\end{array}$ & $\begin{array}{l}\text { 08-Jun-96 } \\
5\end{array}$ & $\begin{array}{l}\text { 09-Jun-96 } \\
6\end{array}$ \\
\hline \multicolumn{7}{|l|}{ Feeds, $g$} \\
\hline $\begin{array}{l}\text { Fresh Feed (Coal+Hondo Oil+ASR) } \\
\text { Make-up Oil }\end{array}$ & $\begin{array}{c}9746 \\
57515\end{array}$ & $\begin{array}{l}31366 \\
7225\end{array}$ & 33575 & 33948 & 35563 & 31880 \\
\hline Fe/P Slurry Catalyst & 136.69 & 264.34 & 307.10 & 310.51 & 311.64 & 291.60 \\
\hline Molyvan-A & 2.17 & 6.24 & 5.27 & 5.33 & 5.35 & 5.01 \\
\hline H2S/Precip. Sulfur & 1170 & 1050 & 1101 & 1061 & 1019 & 1093 \\
\hline TNPS & 2645 & 2736 & 2742 & 2755 & 2654 & 2296 \\
\hline PFL 850 F+ & & 19462 & 15681 & 19985 & 20032 & 13912 \\
\hline PFL 850 F- & 1675 & 22606 & 26113 & 22512 & 24365 & 20087 \\
\hline $\begin{array}{l}\text { 1st St SOH - OIL } \\
\text { 2nd St SOH - OIL } \\
\text { SOH - H2O } \\
\text { PFL (O-3 Bttms) }\end{array}$ & & & & & & \\
\hline PFC (O-3 Bttms) & & & & 572 & 739 & 1394 \\
\hline Water & 9671 & 10130 & 9534 & 8606 & 7156 & 10275 \\
\hline Hydrogen Feed & 7395 & 7395 & 7394 & 7387 & 7395 & 7392 \\
\hline TOTAL FEED & 89956 & 102241 & 96452 & 97141 & 99240 & 88624 \\
\hline \multicolumn{7}{|l|}{ Products, $\mathrm{g}$} \\
\hline Hydrogen in Product Gases & 6661 & 5733 & 5611 & 5299 & 5312 & 5359 \\
\hline Product Gas (hydrogen \& nitrogen free & 9811 & 10640 & 10960 & 9806 & 9585 & 9210 \\
\hline PFL $850 \mathrm{Ft}$ & 21097 & 19597 & 21026 & 17558 & 20484 & 21266 \\
\hline $\begin{array}{l}\text { PFL } 850 \text { F- } \\
\text { 1st St SOH - OIL }\end{array}$ & 33781 & 27175 & 21976 & 29469 & 30722 & 28076 \\
\hline 2nd St SOH - OIL & 8683 & 13451 & 16598 & 13846 & 12672 & 11084 \\
\hline $\begin{array}{l}\text { SOH - H2O } \\
\text { PFL (O-3 Bttms) }\end{array}$ & 10728 & 15403 & 19988 & 14480 & 12669 & 15123 \\
\hline PFC (O-3 Bttms) & 3671 & 6602 & 6738 & 7452 & 8592 & 3962 \\
\hline TOTAL PRODUCTS & 94432 & 98600 & 102897 & 97910 & 100037 & 94079 \\
\hline RECOVERY, W\% & 104.98 & 96.44 & 106.68 & 100.79 & 100.80 & 106.16 \\
\hline Liquid Closure, W\% & 94.43 & 86.70 & 96.93 & 92.26 & 92.70 & 97.88 \\
\hline Metered $\mathrm{H} 2$ Cons., W\% maf coal & 8.28 & 5.83 & 5.84 & 6.76 & 6.44 & 7.01 \\
\hline Metered H2 Cons., W\% maf fresh feed & 8.28 & 5.83 & 5.84 & 6.76 & 6.44 & 7.01 \\
\hline \multicolumn{7}{|l|}{ UN-NORMALIZED GAS YIELDS, W\% maf c } \\
\hline K-1 \& K-2 : C1-C3 Gas Yield & 29.29 & 12.41 & 12.06 & 10.93 & 10.09 & 10.76 \\
\hline K-1 \& K-2 : C4-C7 Gas Yield & 14.67 & 4.37 & 4.24 & 3.75 & 3.54 & 4.09 \\
\hline K-1 \& K-2 : COx Gas Yield & 16.20 & 7.77 & 6.92 & 6.71 & 6.66 & 6.61 \\
\hline $\mathrm{K}-1: \mathrm{C} 1-\mathrm{C} 3 \mathrm{Gas}$ Yield & 12.77 & 6.03 & 5.80 & 5.53 & 5.30 & 5.92 \\
\hline K-1 : C4-C7 Gas Yield & 6.37 & 2.24 & 1.88 & 1.74 & 1.67 & 2.18 \\
\hline K-1 : cox Gas Yield & 15.73 & 7.29 & 6.43 & 6.31 & 6.05 & 6.17 \\
\hline $\begin{array}{l}\% \text { Total C1-C3 from Stage } 1 \\
\% \text { Total C4-C7 from Stage } 1\end{array}$ & 43.60 & 48.61 & 48.13 & 50.56 & 52.51 & 55.06 \\
\hline \% Total C4-C7 from Stage 1 & 43.43 & 51.27 & 44.41 & 46.38 & 47.20 & 53.32 \\
\hline $\begin{array}{l}\text { Dry Coal Feed, } 9 \\
\text { Calculated Coal Moisture Content, w\% }\end{array}$ & $\begin{array}{l}9453 \\
3.00\end{array}$ & $\begin{array}{c}30425 \\
3.00\end{array}$ & $\begin{array}{c}32568 \\
3.00\end{array}$ & $\begin{array}{c}32930 \\
3.00\end{array}$ & $\begin{array}{c}34496 \\
3.00\end{array}$ & $\begin{array}{c}30923 \\
3.00\end{array}$ \\
\hline
\end{tabular}


227-95 Condition 3 Results

Co-processing of Auto-Fluff and/or Waste Plastics with Coal/Petroleum Resid

DATE

PERIOD

FEEDS, $g$

Fresh Feed (Coal+Hondo Oil+ASR)

Make-up Oil

Fe/P Slurry Catalyst

Molyvan-A

H2S/Precip. Sulfur

TNPS

PFL $850 \mathrm{~F}+$

PFL $850 \mathrm{~F}$ -

PR3

PR4

ASOH

1st St SOH - OIL

2nd St SOH - OIL

$\mathrm{SOH}-\mathrm{H} 2 \mathrm{O}$

PFL (O-3 Bttms)

PFC (O-3 Bttms)

Water

Hydrogen Feed

TOTAL FEED

Products, $g$

Hydrogen in Product Gases

Product Gas (hydrogen \& nitrogen free)

PFL 850 F+

PFL $850 \mathrm{~F}$.

PR3

PR4

ASOH

1st St SOH - OIL

2nd St SOH - OIL

$\mathrm{SOH}-\mathrm{H} 2 \mathrm{O}$

PFL (O-3 Bttms)

PFC (O-3 Bttms)

TOTAL PRODUCTS

RECOVERY, W\%

Liquid Closure, W\%

Metered H2 Cons., W\% maf coal

Metered H2 Cons., W\% maf fresh feed

UN-NORMALIZED GAS YIELDS, W\% maf coal

K-1 \& K-2 : C1-C3 Gas Yield

K-1 \& K-2 : C4-C7 Gas Yield

K-1 \& K-2 : COx Gas Yield

$\mathrm{K}-1$ : C1-C3 Gas Yield

K-1 : C4-C7 Gas Yield

$\mathrm{K}-1$ : COx Gas Yield

$\%$ Total C1-C3 from Stage 1

$\%$ Total C4-C7 from Stage 1

Dry Coal Feed, $g$

Calculated Coal Moisture Content, W\%
10-Jun-96$$
7
$$

14610
20547
144
2
1056
2292
8448
9030

2972

10190

7370

76662

5824

5568

11770

26493

4457

10116

7395

87616

6082

9219

24849

23790

1474

10119

7395

92673

6010

9141

24677

23968

4124

473

10027

7383

89967

5994

8129

26728

20401
14-Jun-96

11

30742

296

5

1076

2757
15-Jun-96

12

29452

285

5

1038

2611
1092

12098

3990

76668

100.01

94.20

11.63

11.63

14.28

5.71

0.37

6.12

1.97

0.33

42.82

34.50

14171

3.00
10215

12966

4974

92095

105.11

95.73

4.81

4.81

11.51

3.93

5.75

5.59

1.72

5.39

48.58

43.74

29093

3.00
10707

12593

5577

92673

100.00

90.91

6.12

6.12

13.92

4.67

6.64

6.42

1.98

6.19

46.11

42.29

24132

3.00

\section{7 \\ 12864 \\ 6083 \\ 91057 \\ 101.21 \\ 93.16 \\ 5.17 \\ 5.17 \\ 10.22 \\ 3.47 \\ 4.08 \\ 4.68 \\ 1.48 \\ 3.75 \\ 45.77 \\ 42.78 \\ 28651 \\ 3.00}

30467

1996

9961

7395

84695

6005

8021
28821

2337

10042

7308

81899

5905

7508
12913

12393

39389

6037

84146

102.74

94.83

5.23

5.23

9.32

3.61

2.87

3.80

1.45

2.57

40.79

40.24

28569

3.00 
227-95 Condition 2 Results

Co-processing of Auto-Fluff and/or Waste Plastics with Coal/Petroleum Resid

DATE

FEEDS, g

Fresh Feed (Coal+Hondo Oil+ASR)

Make-up Oil

Fe/P Slurry Catalyst

Molyvan-A

H2S/Precip. Sulfur

TNPS

PFL $850 \mathrm{~F}+$

PFL 850 F-

PFL (O-3 Bttms)

PFC (O-3 Bttms)

Water

Hydrogen Feed

TOTAL FEED

Products, $\mathbf{g}$

Hydrogen in Product Gases

Product Gas (hydrogen \& nitrogen free)

PFL $850 \mathrm{~F}+$

PFL 850 F.

1st St SOH - OlL

2nd St SOH - OIL

$\mathrm{SOH}-\mathrm{H} 2 \mathrm{O}$

PFL (O-3 Bttms)

PFC (O-3 Bttms)

TOTAL PRODUCTS

RECOVERY, W\%

Liquid Closure, W\%

Metered $\mathrm{H} 2$ Cons., W\% maf fresh feed

UN-NORMALIZED GAS YIELDS, W\% maf coal

K-1 \& K-2 : C1-C3 Gas Yield

K-1 \& K-2 : C4-C7 Gas Yield

K-1 \& K-2 : COx Gas Yield

K-1 : C1-C3 Gas Yield

K-1 : C4-C7 Gas Yield

K-1 : COx Gas Yield

$\%$ Total C1-C3 from Stage 1

\% Total C4-C7 from Stage 1

Dry Coal Feed, $\mathbf{g}$

Calculated Coal Moisture Content, W\%

$$
\text { 16-Jun-96 }
$$

13

$\begin{array}{cc}32551 & 31370 \\ 368.28 & 319.81 \\ 6.32 & 5.49 \\ 1004 & 1038 \\ 2665 & 2737\end{array}$

28847

3236

10053

7375

86106

5780

6766

13823

11805

41054

7300

86528

100.49

93.97

5.38

6.61

3.61

0.87

2.42

1.52

0.78

36.59

42.11

31574

3.00

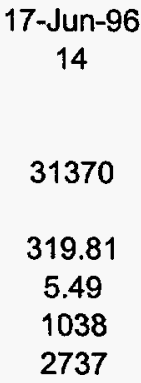

31999

2815

9943

7201

87429

6599

7079

11786

11115

43118

5006

84703

96.88

88.53

2.11

7.19

3.19

0.64

2.91

1.57

0.59

40.48

49.37

30429

3.00
18-Jun-96
$15^{*}$

29697

301.92

5.18

1118

2830

32561

2386

9975

7116

85990

6454

7171

12349

10557

46158

3770

86459

100.55

92.34

2.45

8.47

3.80

1.06

3.97

1.64

0.68

46.88

43.22

28806

3.00
19-Jun-96

$16^{\star}$

16575

24145

1190

1530

34700

363

11185

6660

96348

6737

7136

9079

11915

60293

1188

96348

100.00

91.96

$-0.51$

22.06

8.01

0.93

13.50

3.45

0.81

61.18

43.05

16077

3.00
20-Jun-96

$17^{*}$

1881

10452

1198

679

66863

96

10844

7373

99387

7020

5012

8752

8344

69357

1908

100393

101.01

96.03

20.63

88.37

34.59

29.89

30.38

10.48

24.75

34.38

30.30

1825

3.00

* Unit operational difficulties were experienced and the scheduled feed to the unit was interrupted several times. 
227-95 Condition 4 Results

Co-processing of Auto-Fluff and/or Waste Plastics with Coal/Petroleum Resid

DATE

PERIOD

FEEDS, $\mathbf{g}$

Fresh Feed (Coal+ASR)

Make-up Oil

Fe/P Slurry Catalyst

Molyvan-A

H2S/Precip. Sulfur

TNPS

PFL $850 \mathrm{F+}$

PFL 850 F-

1st St SOH - OIL

2nd St SOH - OIL

$\mathrm{SOH}$ - $\mathrm{H} 2 \mathrm{O}$

PFL (O-3 Bttms)

PFC (0-3 Bttms)

Water

Hydrogen Feed

TOTAL FEED

Products, $g$

Hydrogen in Product Gases

Product Gas (hydrogen \& nitrogen free)

PFL $850 \mathrm{~F}+$

PFL $850 \mathrm{~F}$ -

1st St SOH - OIL

2nd St SOH - OIL

$\mathrm{SOH}-\mathrm{H} 2 \mathrm{O}$

PFL (O-3 Bttms)

PFC (O-3 Bttms)

TOTAL PRODUCTS

RECOVERY, W\%

Liquid Closure, W\%

Metered H2 Cons., W\% maf coal

Metered H2 Cons., W\% maf fresh feed

UN-NORMALIZED GAS YIELDS, W\% maf coal

K-1 \& K-2 : C1-C3 Gas Yield

K-1 \& K-2 : C4-C7 Gas Yield

K-1 \& K-2: COx Gas Yield

K-1 : C1-C3 Gas Yield

$\mathrm{K}-1$ : C4-C7 Gas Yield

K-1 : COx Gas Yield

\% Total C1-C3 from Stage 1

$\%$ Total C4-C7 from Stage 1

Dry Coal Feed, $\mathbf{g}$

Calculated Coal Moisture Content, W\%
21-Jun-96

18

33218

313

5

1170

517

52737

695

9239

7373

105268

6610

6684

4285

6752

10931

64876

6550

106688

101.35

95.40

2.52

2.52

7.94

2.88

4.96

2.85

0.90

4.06

35.90

31.33

32222

3.00
22-Jun-96
19

42659

293

5

1266

17
$\underset{20}{23-J u n-96}$

43615

299

1974

37156

1978

10119

7365

102512

6395

6474

7376

3414

2441

12448

61401

9104

102753

101.61

94.72

2.06

2.06

6.84

2.43

3.79

2.06

0.84

2.98

30.16

34.42

41379

3.00
4071

6072

11638

58395

9834

102880

100.36

94.60

2.44

2.44

5.76

2.34

2.91

2.12

1.03

2.38

36.84

43.95

42307

3.00
24-Jun-96

21

42100

289

5

2074
35666

2363

10222

7263

99981

6314

6816

3501

5193

11441

62729

8340

104334

104.35

98.37

2.48

2.48

5.60

5.32

3.16

2.33

2.80

2.67

41.62

52.58

40837

3.00 
227-95 Condition 5 Results

Co-processing of Auto-Fluff and/or Waste Plastics with Coal/Petroleum Resid

DATE

PERIOD

FEEDS, $g$

Fresh Feed (Coal+ASR+Plastics)

Make-up Oil

Fe/P Slurry Catalyst

Molyvan-A

H2S/Precip. Sulfur

TNPS

PFL $850 \mathrm{~F}+$

PFL $850 \mathrm{~F}$ -

1st St SOH - OIL

2nd St SOH - OIL

$\mathrm{SOH}-\mathrm{H} 2 \mathrm{O}$

PFL (O-3 Bttms)

PFC (0-3 Bttms)

Water

Hydrogen Feed

TOTAL FEED

Products, $\mathbf{g}$

Hydrogen in Product Gases

Product Gas (hydrogen \& nitrogen free)

PFL $850 \mathrm{F+}$

PFL 850 F-

1 st St SOH - OIL

2nd St SOH - OIL

$\mathrm{SOH}-\mathrm{H} 2 \mathrm{O}$

PFL (O-3 Bttms)

PFC (O-3 Bttms)

TOTAL PRODUCTS

RECOVERY, W\%

Liquid Closure, W\%

Metered H2 Cons., W\% maf coal

Metered H2 Cons., W\% maf fresh feed

UN-NORMALIZED GAS YIELDS, W\% maf coal

K-1 \& K-2 : C1-C3 Gas Yield

K-1 \& K-2 : C4-C7 Gas Yield

K-1 \& K-2 : COX Gas Yield

K-1 : C1-C3 Gas Yield

K-1 : C4-C7 Gas Yield

K-1 : COx Gas Yield

$\%$ Total C1-C3 from Stage 1

$\%$ Total C4-C7 from Stage 1

Dry Coal Feed, $g$

Calculated Coal Moisture Content, W\%

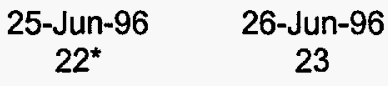

26464

7250

260

5

1782

23140

228

4

1673

$\begin{array}{cc}48309 & 43267 \\ 2036 & 1750 \\ 9772 & 10112 \\ 7267 & 7143 \\ & \\ 103145 & 87318\end{array}$

* Unit operational difficulties were experienced and the scheduled feed to the unit was interrupted. 
PB-04: Normalized Yields of Gaseous Products

$\begin{array}{cccccc}\text { Periods } & 5 & 12 & 14 / 15 & 21 & 23 \\ \text { C1 } & 3.82 & 3.11 & 2.23 & 2.55 & 2.59 \\ \text { C2 } & 2.85 & 2.34 & 1.87 & 2.00 & 2.81 \\ \text { C3 } & 3.23 & 3.10 & 2.87 & 2.36 & 2.43 \\ \text { C4 } & 1.63 & 1.52 & 1.31 & 1.64 & 1.76 \\ \text { C5 } & 0.88 & 0.97 & 1.28 & 0.53 & 0.70 \\ \text { C6-C7 } & 0.96 & 0.82 & 0.50 & 4.39 & 5.69\end{array}$

